\title{
Lewis Base Activation of Lewis Acids: Development of a Lewis Base Catalyzed Selenolactonization.
}

\author{
Scott E. Denmark* and William R. Collins \\ Roger Adams Laboratory, Department of Chemistry, University of Illinois, Urbana, Illinois, \\ 61801
}

\section{SUPPORTING INFORMATION}

Table of Contents

Page

General Experimental

Literature Preparations

Experimental Procedures

Selenenamide Survey

Lewis Base Survey

React-IR Rate Data

Mechanistic Studies

References

\section{General Experimental}

All reactions were performed in oven-dried $\left(140^{\circ} \mathrm{C}\right)$ or flame-dried glassware under an inert atmosphere of dry argon. All reaction temperatures correspond to internal temperatures measured by Teflon-coated thermocouples unless otherwise noted. The reaction solvents dichloromethane (Fisher, HPLC grade) and tetrahydrofuran (Fisher, HPLC grade) were dried by percolation through two columns packed with neutral alumina under a positive pressure of argon. Deuteroichloroform was percolated through activity 1 alumina and stored over 3 angstrom molecular sieves. Solvents for chromatography, recrystallization and filtration were: hexane (Aldrich, ACS grade), ethyl acetate (Aldrich, ACS grade), and dichloromethane (Aldrich, ACS grade). Solvents for extraction: dichloromethane $\left(\mathrm{CH}_{2} \mathrm{Cl}_{2}\right)$, ethyl acetate (EtOAc), and hexane were reagent grade. Triethylamine $\left(\mathrm{Et}_{3} \mathrm{~N}\right)$ was freshly distilled from $\mathrm{CaH}_{2}$ before use. Acetic acid $(\mathrm{AcOH})$ was freshly distilled from $\mathrm{CrO}_{3}$ and acetic anhydride prior to use. Commercial reagents were purified by distillation or recrystallization prior to use. Column chromatography was performed using EM Science 230-400-mesh silica gel. 
${ }^{1} \mathrm{H}$ NMR, and ${ }^{13} \mathrm{C}$ NMR spectra were recorded on Varian Unity $400\left(400 \mathrm{MHz},{ }^{1} \mathrm{H} ; 100\right.$ $\left.\mathrm{MHz},{ }^{13} \mathrm{C}\right)$, Unity-500 $\left(500 \mathrm{MHz}{ }^{1} \mathrm{H}, 125 \mathrm{MHz}{ }^{13} \mathrm{C}\right)$ and Varian Unity Inova $500\left(500 \mathrm{MHz}{ }^{1} \mathrm{H}\right)$ spectrometers in deuteriochloroform unless otherwise stated. Spectra were referenced to residual chloroform (7.26 ppm, ${ }^{1} \mathrm{H}, 77.23 \mathrm{ppm},{ }^{13} \mathrm{C}$,). ${ }^{77} \mathrm{Se}$ NMR and ${ }^{31} \mathrm{P}$ NMR spectra were recorded on a Varian Unity $600\left(600 \mathrm{MHz},{ }^{1} \mathrm{H} ; 114.4 \mathrm{MHz},{ }^{77} \mathrm{Se}, 161.9 \mathrm{MHz}{ }^{31} \mathrm{P}\right)$ spectrometer in deuteriochloroform. Spectra were internally referenced to diphenyl diselenide (462.2 ppm) for ${ }^{77} \mathrm{Se}$ NMR or externally referenced to phosphoric acid $\left(40 \%\right.$ in $\left.\mathrm{H}_{2} \mathrm{O}, 0.0 \mathrm{ppm}\right)$ for ${ }^{31} \mathrm{P}$ NMR. Chemical shifts are reported in ppm, multiplicities are indicated by $s$ (singlet), $d$ (doublet), $t$ (triplet), q (quartet), p (pentet), h (hextet), m (multiplet) and br (broad). Coupling constants, $J$, are reported in Hertz. Spectra are available on request from denmark@scs.uiuc.edu. Mass spectrometry was performed by the University of Illinois Mass Spectrometer Center. EI and CI mass spectra were performed on a 70-VSE-B spectrometer. Data are reported in the form of $(\mathrm{m} / \mathrm{z})$. Infared spectra (IR) were recorded on a Mattson Galaxy 5020 spectrophotometer in $\mathrm{NaCl}$ cells. Peaks are recorded in $\mathrm{cm}^{-1}$ with indicated relative intensities: $\mathrm{s}$ (strong, 67-100\%); m (medium, 34-66\%); and w (weak, 0-33\%). ReactIR experiments were performed on an ASI ReactIR 1000 optics module fitted with a 5/8 inch Dicomp probe. Melting points (mp) were determined in sealed tubes and are corrected. Kugelrohr distillation temperatures reported are air bath temperatures $(\mathrm{ABT})$. Analytical thin-layer chromatography was performed on Merck silica gel plates with F-254 indicator. Visualization was accomplished by UV light, potassium permanganate solution $\left(\mathrm{KMnO}_{4}\right)$, phosphomolybdic acid (PMA), iodine absorbed onto silica gel $\left(\mathrm{I}_{2}\right)$ and ceric ammonium molybdate stain $(\mathrm{CAM})$.

\section{Literature preparations}

The preparation of (E)-4-phenyl-3-butenoic acid $\mathbf{1}$ as well as trimethylsilyl (E)-4-phenyl3-butenoic ester $\mathbf{2 4}$ followed the procedure developed by Denmark and Edwards ${ }^{1}$. Benzeneselenenyl chloride was prepared following the procedure described by Schmid and Garratt and was recrystallized from $\mathrm{CH}_{2} \mathrm{Cl}_{2} /$ hexane $^{2}$. 1-Trimethylsilyltetrazole ${ }^{3}$, 1$\begin{array}{lllll}\text { trimethylsilylbenzotriazole } & 4\end{array}, \quad N$-phenylselenenylsuccinimide $\quad 6 \quad$ NPSS $^{5}, \quad N$ phenylselenenylphthalimide 5 (NPSP) ${ }^{6}$, (Z)-4-phenyl-3-butenoic acid $\mathbf{1 1}^{7}$, tris(dimethylamino)phosphine sulfide ${ }^{8}$, tris(dimethylamino)phosphine selenide $\mathbf{9}^{8}$, and triphenylphosphine sulfide ${ }^{8}$, tricyclohexylphosphine sulfide $^{9}, \quad 1,3$-dimethylhexahydropyrimidine-2-thione ${ }^{10}$, and $N, N^{\prime}-$ dimethyl diphenylphosphoramidite ${ }^{11}$ were prepared according to literature procedure. 


\section{Experimental Procedures:}

\section{Preparation of 1-(Phenylseleno)-1 $H$-tetrazole (2) ${ }^{12}$ [WRC-XII-064]}

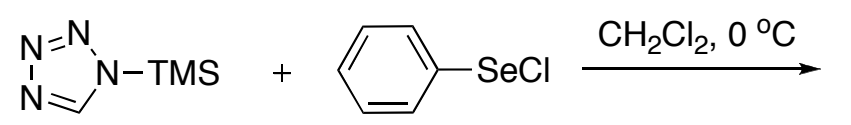

16

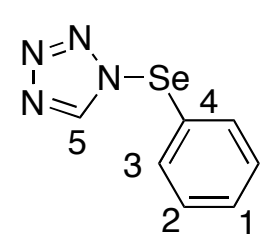

2

A flame-dried, 25-mL Schlenk flask was charged with trimethylsilyltetrazole $16(750 \mathrm{mg}$, $5.27 \mathrm{mmol}, 1.0$ equiv) and $\mathrm{CH}_{2} \mathrm{Cl}_{2}(5 \mathrm{~mL})$. The colorless solution was cooled to $0{ }^{\circ} \mathrm{C}$ (ice bath) before a solution of benzeneselenenyl chloride (1.01 g, $5.27 \mathrm{mmol}, 1.0$ equiv) in $\mathrm{CH}_{2} \mathrm{Cl}_{2}(4 \mathrm{~mL})$ was added via cannula over 10 minutes. After an additional 20 minutes the ice bath was removed and the solution was allowed to stir at room temperature overnight ( $22 \mathrm{~h})$. The solvent was then removed in vacuo directly on the manifold $(0.01 \mathrm{~mm} \mathrm{Hg})$ to give a brown solid. After backfilling with argon, $\mathrm{CH}_{2} \mathrm{Cl}_{2}(5 \mathrm{~mL})$ was added via syringe and the brown solution was heated in an oil bath to reflux $\left(50{ }^{\circ} \mathrm{C}\right)$ for 10 minutes. After the solution cooled to room temperature, $\mathrm{Et}_{2} \mathrm{O}(5$ $\mathrm{mL}$ ) was added via syringe and the solution was cooled to $0{ }^{\circ} \mathrm{C}$ (ice bath). The brown supernatant was removed using cannula filtration. The tan solid was further washed with $\mathrm{Et}_{2} \mathrm{O}(3 \times 5 \mathrm{~mL})$ with subsequent filtration. The off-white solid was placed on high vacuum $(0.01 \mathrm{~mm} \mathrm{Hg})$ overnight to give $996 \mathrm{mg}(84 \%)$ of the extremely hydrolytically sensitive product 2 . All further manipulations of this compound were performed in a dry box.

Data for 1-(phenylseleno)-1H-tetrazole (2):

mp: $\quad 96-98{ }^{\circ} \mathrm{C}(\mathrm{dec})$

${ }^{1} \underline{\text { H NMR: }} \quad\left(500 \mathrm{MHz}, \mathrm{CDCl}_{3}\right)$

$8.69(\mathrm{~s}, 1 \mathrm{H}, \mathrm{CH}(5)), 7.86\left(\mathrm{~d}, J=7.0 \mathrm{~Hz}, 2 \mathrm{H}, \mathrm{CH}\left(3,3^{\prime}\right)\right)$, 7.41-7.50 (m, $3 \mathrm{H}$, $\left.\mathrm{CH}\left(1,2,2^{\prime}\right)\right)$

${ }^{13}$ C NMR: $\quad\left(126 \mathrm{MHz}, \mathrm{CDCl}_{3}\right)$

$150.10(\mathrm{C}(5)), 135.00,131.72,130.60,130.16,130.06(\mathrm{C}(4))$

${ }^{77}$ Se NMR: $\quad\left(114 \mathrm{MHz}, \mathrm{CDCl}_{3}\right)$

970.0

$\underline{\mathrm{MS}}: \quad(\mathrm{EI}+, 70 \mathrm{eV})$

157 (M-tetrazole, 100), 117 (10), 105 (3) 
Compound 2 was unstable to a variety of MS techniques. The other major peaks were: 234 (diphenyl selenide, 23), 314 (diphenyl diselenide, 84)

Analysis: $\quad \mathrm{C}_{7} \mathrm{H}_{6} \mathrm{~N}_{4} \mathrm{Se}(225.11)$

Calcd: C, 37.35; H, 2.69; N, 24.89; Se, 28.80;

Found: C, 37.42; H, 2.59; N, 24.41; Se, 30.34;

Preparation of 1-(Phenylseleno)-1H-benzo[d] [1,2,3]triazole (3) ${ }^{12}$ [WRC-XII-42]

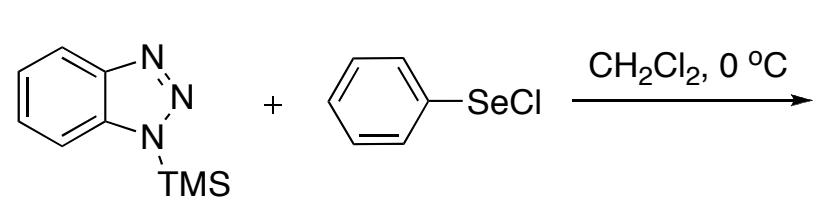

17

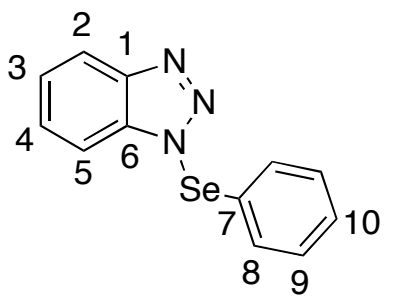

3

A flame-dried, 25-mL Schlenk flask was charged with trimethylsilyl benzotriazole 17 (2.00 g, $10.45 \mathrm{mmol}, 1.0$ equiv) and $\mathrm{CH}_{2} \mathrm{Cl}_{2}(12.1 \mathrm{~mL})$. The colorless solution was cooled with an ice bath to $0{ }^{\circ} \mathrm{C}$ before a solution of benzeneselenenyl chloride $(2.00 \mathrm{~g}, 10.45 \mathrm{mmol}, 1$ equiv) in $\mathrm{CH}_{2} \mathrm{Cl}_{2}(4 \mathrm{~mL})$ was added via cannula over 10 minutes. After an additional 20 minutes the ice bath was removed and the solution was allowed to stir at room temperature overnight (22 h). The solvent was then removed in vacuo directly on the manifold $(0.01 \mathrm{~mm} \mathrm{Hg})$ to give a yellow solid. Continuous vacuum was applied for an additional $3 \mathrm{~h}$ to remove the remaining TMSCl. After backfilling the flask with argon, $\mathrm{CH}_{2} \mathrm{Cl}_{2}(5 \mathrm{~mL})$ and $\mathrm{Et}_{2} \mathrm{O}(10 \mathrm{~mL})$ were added via syringe. The yellow supernatant was then removed by cannula filtration. The pale crystals were further washed with $\mathrm{Et}_{2} \mathrm{O}(2 \times 10 \mathrm{~mL})$ and subsequently filtered. The white solid was dried overnight under high vacuum on the manifold $(0.01 \mathrm{~mm} \mathrm{Hg})$ to give $2.11 \mathrm{~g}(82 \%)$ of extremely hydrolytically sensitive product 3 . All further manipulations of this compound were performed in a dry box.

Data for 1-(phenylseleno)-1H-benzo[d][1,2,3]triazole (3):

mp: $\quad 109-118{ }^{\circ} \mathrm{C}(\mathrm{dec})$

${ }^{1} \underline{\mathrm{H} \mathrm{NMR}}: \quad\left(500 \mathrm{MHz}, \mathrm{CDCl}_{3}\right)$

$8.06(\mathrm{~d}, J=8.5 \mathrm{~Hz}, 1 \mathrm{H}, \mathrm{CH}(2))$, 7.66-7.70 (m, $3 \mathrm{H}, \mathrm{CH}(3-5,8-9)), 7.53$ (t, $J=8.0$

$\mathrm{Hz}, 1 \mathrm{H}, \mathrm{CH}(10))$, 7.31-7.37 (m, 4 H, CH(3-5,8-9)) 
${ }^{13}$ C NMR: $\quad\left(126 \mathrm{MHz}, \mathrm{CDCl}_{3}\right)$

$145.18(\mathrm{C}(1)), 138.42(\mathrm{C}(6)), 132.89,131.53,130.19,129.77,128.27,124.20$, $120.04,111.15$

${ }^{77}$ Se NMR: $\quad\left(114 \mathrm{MHz}, \mathrm{CDCl}_{3}\right)$

860.5

MS: $\quad(\mathrm{EI}+, 70 \mathrm{eV})$

313.9 (63), 275.0 (M+1, 64), 246 (63), 221 (6), 195 (1), 167 (100), 157 (96), 140

(8), $119(55)$

Analysis: $\quad \mathrm{C}_{12} \mathrm{H}_{9} \mathrm{~N}_{3} \mathrm{Se}(274.18)$

Calcd: C, 52.57; $\quad$ H, 3.31; $\quad$ N, 15.33; $\quad$ Se, 35.08

Found: C, $52.40 ; \quad$ H, 3.22; $\quad$ N, 15.11; $\quad$ Se, 33.82

Preparation of $( \pm)-r e l-(4 R, 5 R)$-Dihydro-4-(phenylseleno)-5-phenylfuran-2(3H)-one (12) [WRC-XIII-061]

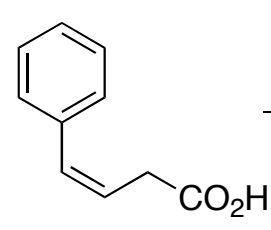

11

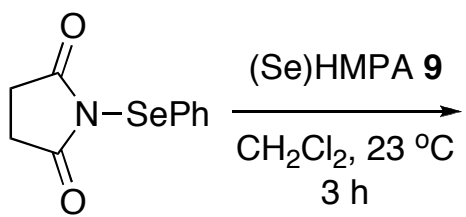

6

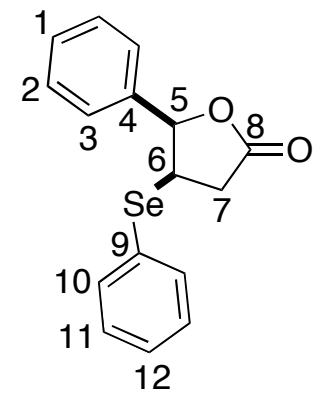

12

A flame-dried, $10-\mathrm{mL}$ Schlenk flask was charged with $\mathrm{N}$-phenylselenylsuccinimide $\mathbf{6}$ (153 mg, $0.6 \mathrm{mmol}, 1.2$ equiv) and selenophosphoramide 9 (12 $\mathrm{mg}, 0.05 \mathrm{mmol}, 0.1$ equiv) in the dry box. The flask was reattached to the manifold and diluted with $\mathrm{CH}_{2} \mathrm{Cl}_{2}(3.5 \mathrm{~mL})$. To the light yellow solution was added (Z)-phenyl-4-butenoic acid 11 in $\mathrm{CH}_{2} \mathrm{Cl}_{2}(1.5 \mathrm{~mL})$ drop wise over 5 minutes. The bright yellow reaction mixture stirred for $3 \mathrm{~h}$ and then was concentrated in vacuo directly on the manifold $(0.01 \mathrm{~mm} \mathrm{Hg})$ to give an orange oil. The crude material was purified by column chromatography $\left(\mathrm{SiO}_{2}, 85 \mathrm{~g}, 30 \mathrm{~mm} \times 45 \mathrm{~cm}, 8: 1\right.$ then $6: 1$ then $4: 1$ hexanes/ethyl acetate) to afford $150 \mathrm{mg}(94 \%)$ of $( \pm)-\mathbf{1 2}$ as a white solid.

Data for $( \pm)$-rel-(4R,5R)-Dihydro-4-(phenylseleno)-5-phenylfuran-2(3H)-one (12):

mp: $\quad 94-96{ }^{\circ} \mathrm{C}(\mathrm{dec})$ 


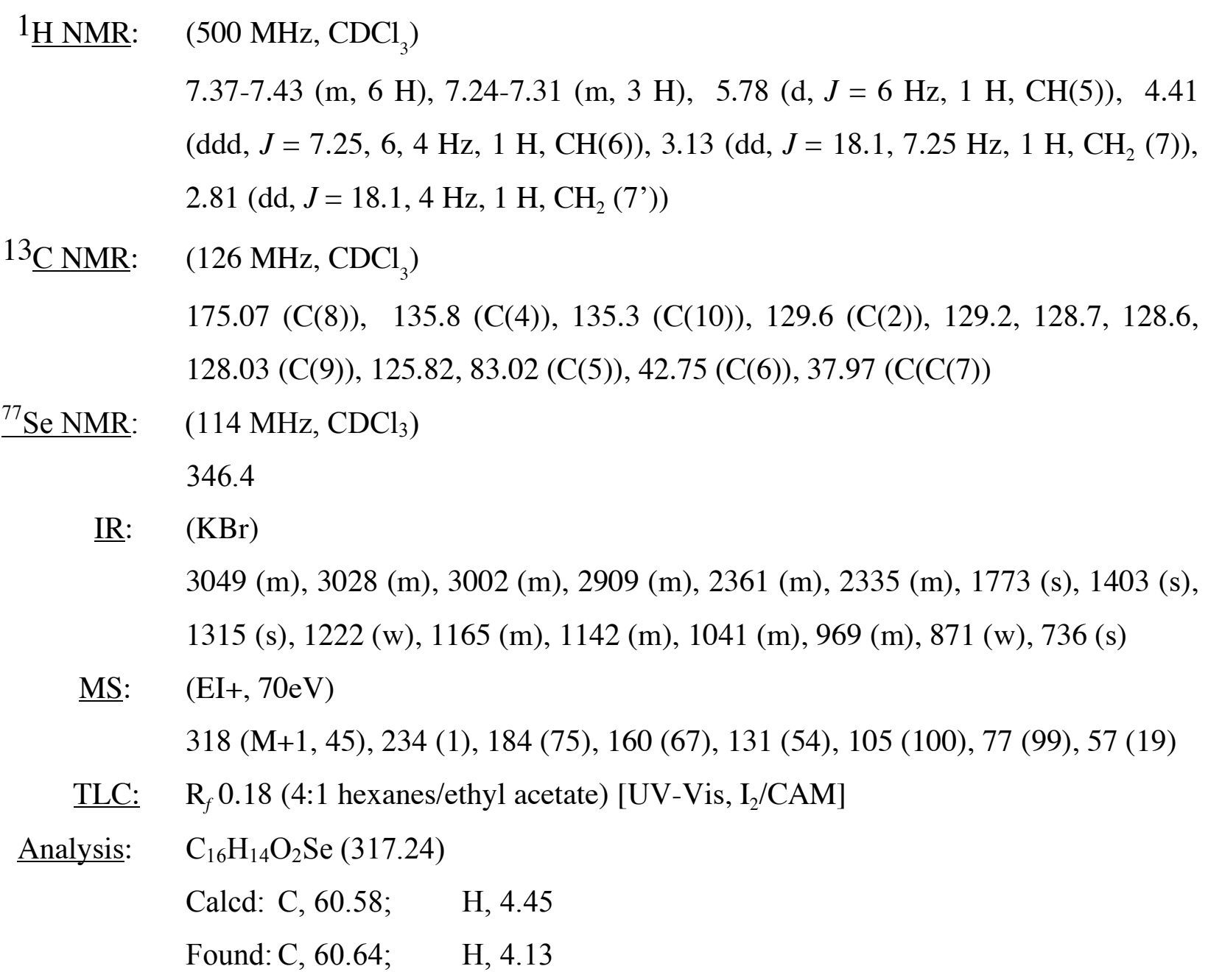

\section{Selenenamide Survey:}

General Procedure I: Background Selenolactonizations of (E)-4-Phenyl-3-butenoic acid with Selenenamides

To a flame-dried, 5-mL Schlenk flask equipped with a stir bar under argon was added the selenenamide (0.24 mmol, 1.2 equiv) in the dry box. After removal from the dry box and reattachment of the flask to a manifold, the selenenamide was diluted with $\mathrm{CH}_{2} \mathrm{Cl}_{2}(1 \mathrm{~mL})$. To the colorless solution was added $(E)$-4-phenyl-3-butenoic acid $\mathbf{1}$ in one portion. The light yellow colored solution was allowed to stir for $3 \mathrm{~h}$ at room temperature before it was concentrated in vacuo directly on the manifold $(0.01 \mathrm{~mm} \mathrm{Hg})$ to afford the crude oil. The residue was directly purified by column chromatography $\left(\mathrm{SiO}_{2}, 30 \mathrm{~mm}\right.$ x $45 \mathrm{~cm}, 10: 1$ hexanes/ethyl acetate) to afford the pure product as a light pink oil. 
Preparation of $( \pm)-r e l-(4 R, 5 S)$-Dihydro-4-(phenylseleno)-5-phenylfuran-2(3H)-one (2) from N-Phenylselenyltetrazole (3) [WRC-XIII-050]

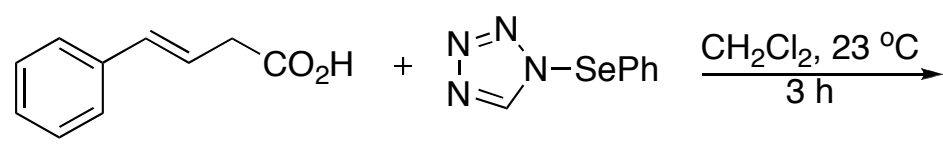

1

3

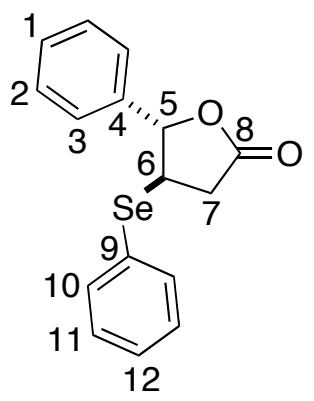

2

Following General Procedure I, $N$-phenylselenyltetrazole 3 (45 mg, 0.24 mmol, 1.2 equiv) was dissolved in $\mathrm{CH}_{2} \mathrm{Cl}_{2}(2 \mathrm{~mL})$. To this was added 1 (32 mg, $0.2 \mathrm{mmol}, 1.0$ equiv). After $3 \mathrm{~h}$ the heterogeneous yellow solution was concentrated in vacuo to give a thick yellow oil. This was directly purified by column chromatography $\left(\mathrm{SiO}_{2}, 50 \mathrm{~g}, 30 \mathrm{~mm}\right.$ x $45 \mathrm{~cm}, 10: 1$ hexanes/ethyl acetate) to afford $55 \mathrm{mg}(87 \%)$ of $( \pm)-2$.

Data for $( \pm)$-rel-(4R,5S)-dihydro-4-(phenylseleno)-5-phenylfuran-2(3H)-one (2) ${ }^{1}$ :

${ }^{1}$ H NMR: $\quad\left(500 \mathrm{MHz}, \mathrm{CDCl}_{3}\right)$

7.52-7.55 (m, $2 \mathrm{H}, \mathrm{CH}(10))$, 7.35-7.39 (m, $4 \mathrm{H}, \mathrm{CH}(1,2,12))$, 7.28-7.33 (m, $4 \mathrm{H}$, $\mathrm{CH}(3,11)), 5.38(\mathrm{~d}, J=6.9 \mathrm{~Hz}, 1 \mathrm{H}, \mathrm{CH}(5)), 3.76(\mathrm{ddd}, J=8.3,8.3,6.9,1 \mathrm{H}$, $\mathrm{CH}(6)), 3.04\left(\mathrm{dd}, J=18.1,8.3 \mathrm{~Hz}, 1 \mathrm{H}, \mathrm{CH}_{2}(7)\right), 2.68(\mathrm{dd}, J=18.1,8.3 \mathrm{~Hz}, 1 \mathrm{H}$, $\left.\mathrm{CH}_{2}\left(7^{\prime}\right)\right)$

${ }^{13} \underline{\mathrm{C} \mathrm{NMR}}: \quad\left(126 \mathrm{MHz}, \mathrm{CDCl}_{3}\right)$

174.46 (C(8), 137 (C(4)), 136 (C(10), 130 (C(2), 129, 128.8, 128.7 (C(11)), 126 (C(9), 125.5 (C(3)), 86.4 (C(5)), 42.1 (C(6)), 35.9 (C(7))

MS: $\quad(\mathrm{EI}+, 70 \mathrm{eV})$

317.9 (M+1, 9), 243 (38), 198.9 (14), 183.9 (10), 161 (3), 131 (2), 119 (100), 91

(5), $76(56)$

IR: (neat)

$3049.1(\mathrm{~m}), 2981.9(\mathrm{~m}), 2300(\mathrm{w}), 1785.6(\mathrm{~m}), 1266.4(\mathrm{~s}), 640(\mathrm{~s})$ 
Preparation of $( \pm)-r e l-(4 R, 5 S)$-Dihydro-4-(phenylseleno)-5-phenylfuran-2(3H)-one (2) from N-Phenylselenylbenzotriazole (4) [WRC-XIII-051]

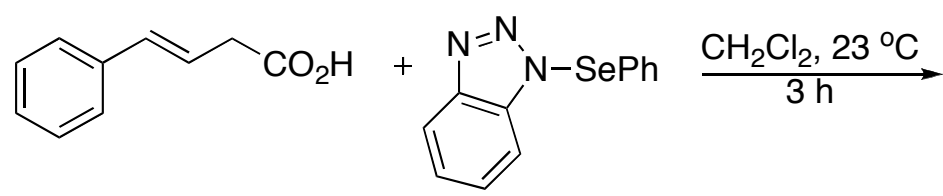

1

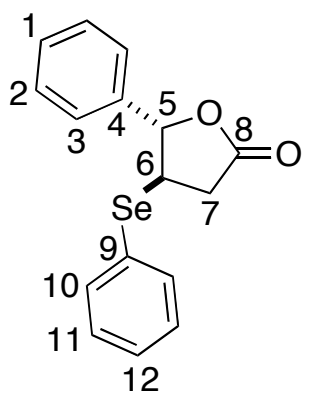

2

Following General Procedure I, $N$-phenylselenylbenzotriazole 4 (66 mg, 0.24 mmol, 1.2 equiv) was dissolved in $\mathrm{CH}_{2} \mathrm{Cl}_{2}(2 \mathrm{~mL})$. To this was added 1 (32 mg, $0.2 \mathrm{mmol}, 1.0$ equiv). After $3 \mathrm{~h}$ the heterogeneous yellow solution was concentrated in vacuo to give a thick yellow oil. This was directly purified by column chromatography $\left(\mathrm{SiO}_{2}, 52 \mathrm{~g}, 30 \mathrm{~mm}\right.$ x $45 \mathrm{~cm}, 10: 1$ hexanes/ethyl acetate) to afford $49 \mathrm{mg}(79 \%)$ of $( \pm)-2$.

Data for $( \pm)$-rel-(4R,5S)-dihydro-4-(phenylseleno)-5-phenylfuran-2(3H)-one $(\mathbf{2})^{\mathbf{1}}$ :

${ }^{1} \underline{\text { H NMR: }} \quad\left(500 \mathrm{MHz}, \mathrm{CDCl}_{3}\right)$

7.52-7.55 (m, 2 H, CH(10)), 7.35-7.39 (m, 4 H, CH(1,2,12)), 7.28-7.33 (m, $4 \mathrm{H}$, $\mathrm{CH}(3,11)), 5.38(\mathrm{~d}, J=6.9 \mathrm{~Hz}, 1 \mathrm{H}, \mathrm{CH}(5)), 3.76(\mathrm{ddd}, J=8.3,8.3,6.9,1 \mathrm{H}$, $\mathrm{CH}(6)), 3.04\left(\mathrm{dd}, J=18.1,8.3 \mathrm{~Hz}, 1 \mathrm{H}, \mathrm{CH}_{2}(7)\right), 2.68(\mathrm{dd}, J=18.1,8.3 \mathrm{~Hz}, 1 \mathrm{H}$, $\left.\mathrm{CH}_{2}\left(7^{\prime}\right)\right)$

Preparation of $( \pm)$-rel-(4R,5S)-Dihydro-4-(phenylseleno)-5-phenylfuran-2(3H)-one (2) from N-Phenylselenylphthalimide (5) [WRC-XIII-052]

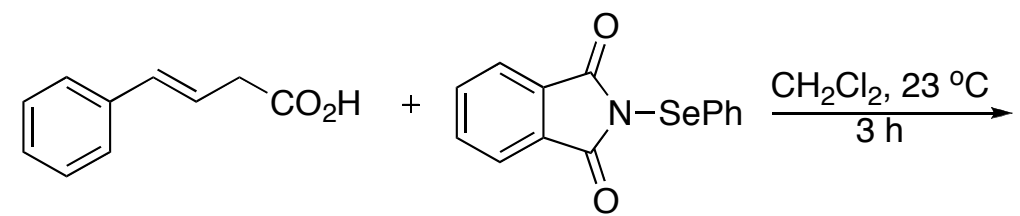

1
5

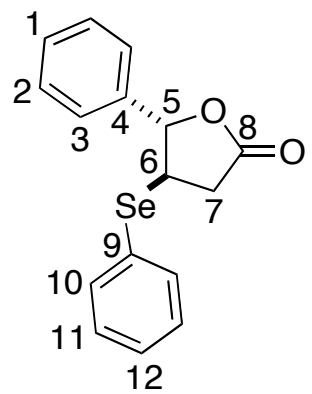

2

Following General Procedure I, N-phenylselenyl phthalimide 5 (73 mg, 0.24 mmol, 1.2 
equiv) was dissolved in $\mathrm{CH}_{2} \mathrm{Cl}_{2}(2 \mathrm{~mL})$. To this was added 1 (32 mg, $0.2 \mathrm{mmol}, 1.0$ equiv). After $3 \mathrm{~h}$ the heterogeneous yellow solution was concentrated in vacuo to give a thick yellow oil. This was directly purified by column chromatography $\left(\mathrm{SiO}_{2}, 51 \mathrm{~g}, 30 \mathrm{~mm} \mathrm{x} 45 \mathrm{~cm}, 10: 1\right.$ hexanes/ethyl acetate) to afford $11 \mathrm{mg}(18 \%)$ of $( \pm)-2$.

$\underline{\text { Data for }( \pm) \text {-rel-(4R,5S)-dihydro-4-(phenylseleno)-5-phenylfuran-2(3H)- one }(2)^{1}}{ }^{\text {: }}$

${ }^{1} \underline{\text { H NMR: }} \quad\left(500 \mathrm{MHz}, \mathrm{CDCl}_{3}\right)$

7.52-7.55 (m, 2 H, CH(10)), 7.35-7.39 (m, 4 H, CH(1,2,12)), 7.28-7.33 (m, 4 H, $\mathrm{CH}(3,11)), 5.38(\mathrm{~d}, J=6.9 \mathrm{~Hz}, 1 \mathrm{H}, \mathrm{CH}(5)), 3.76$ (ddd, $J=8.3,8.3,6.9,1 \mathrm{H}$, $\mathrm{CH}(6)), 3.04\left(\mathrm{dd}, J=18.1,8.3 \mathrm{~Hz}, 1 \mathrm{H}, \mathrm{CH}_{2}(7)\right), 2.68(\mathrm{dd}, J=18.1,8.3 \mathrm{~Hz}, 1 \mathrm{H}$, $\left.\mathrm{CH}_{2}\left(7^{\prime}\right)\right)$

Preparation of $( \pm)-r e l-(4 R, 5 S)$-Dihydro-4-(phenylseleno)-5-phenylfuran-2(3H)-one (2) from N-Phenylselenylsuccinimide (6) [WRC-XII-023]

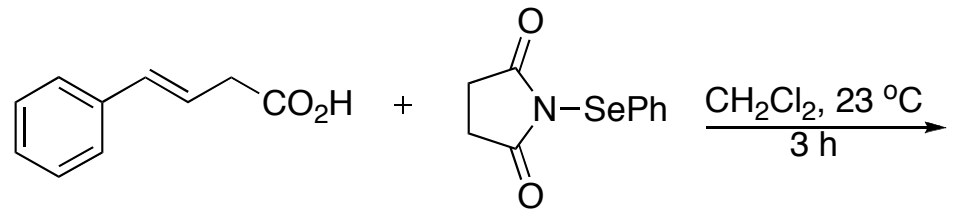

1

6

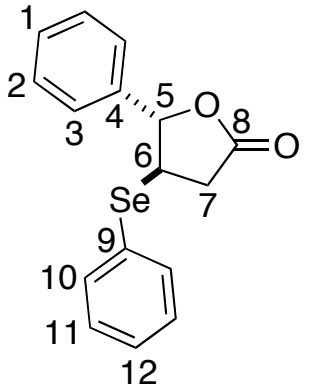

2

Following General Procedure I, $N$-phenylselenylsuccinimide 5 (304 mg, $1.2 \mathrm{mmol}, 1.2$ equiv) was dissolved in $\mathrm{CH}_{2} \mathrm{Cl}_{2}(6.6 \mathrm{~mL})$. To this was added 1 (162 mg, $1.0 \mathrm{mmol}, 1.0$ equiv). After $3 \mathrm{~h}$ the heterogeneous yellow solution was concentrated in vacuo to give a thick yellow oil. This was directly purified by column chromatography $\left(\mathrm{SiO}_{2}, 65 \mathrm{~g}, 30 \mathrm{~mm}\right.$ x $45 \mathrm{~cm}, 10: 1$ hexanes/ethyl acetate) to afford $24.5 \mathrm{mg}(8 \%)$ of $( \pm)-2$.

Data for $( \pm)$-rel-(4R,5S)-dihydro-4-(phenylseleno)-5-phenylfuran-2(3H)-one $(\mathbf{2})^{\mathbf{1}}$ :

${ }^{1} \underline{\mathrm{H} N M R}: \quad\left(500 \mathrm{MHz}, \mathrm{CDCl}_{3}\right)$

7.52-7.55 (m, 2 H, CH(10)), 7.35-7.39 (m, 4 H, CH(1,2,12)), 7.28-7.33 (m, $4 \mathrm{H}$, $\mathrm{CH}(3,11)), 5.38(\mathrm{~d}, J=6.9 \mathrm{~Hz}, 1 \mathrm{H}, \mathrm{CH}(5)), 3.76(\mathrm{ddd}, J=8.3,8.3,6.9,1 \mathrm{H}$, $\mathrm{CH}(6)), 3.04\left(\mathrm{dd}, J=18.1,8.3 \mathrm{~Hz}, 1 \mathrm{H}, \mathrm{CH}_{2}(7)\right), 2.68(\mathrm{dd}, J=18.1,8.3 \mathrm{~Hz}, 1 \mathrm{H}$, $\left.\mathrm{CH}_{2}\left(7^{\prime}\right)\right)$ 


\section{Lewis Base Survey:}

General Procedure II: Selenolactonizations of (E)-4-Phenyl-3-butenoic Acid (1) with $N$ Phenylselenylsuccinimide (6) Catalyzed by Lewis Bases.

To a flame-dried, 10-mL Schlenk flask equipped with a stir bar under argon was added the N-phenylselenyl succinimide 6 (1.2 mmol, 1.2 equiv) in the dry box. After removal from the dry box and reattachment of the flask to a manifold, 6 was diluted with $\mathrm{CH}_{2} \mathrm{Cl}_{2}(5.1 \mathrm{~mL})$. To the colorless solution was added the Lewis base $(0.1 \mathrm{mmol}, 0.1$ equiv) in one portion. This was followed by the addition of (E)-4-phenyl-3-butenoic acid 1 in $\mathrm{CH}_{2} \mathrm{Cl}_{2}(1.5 \mathrm{~mL})$ drop wise over 5 minutes. After $3 \mathrm{~h}$ a saturated aqueous solution of sodium thiosulfate $(2 \mathrm{~mL})$ was added directly to the reaction mixture to quench the remaining $\mathbf{6}$. The biphasic solution was rapidly stirred for an additional $1 \mathrm{~h}$, after which the solution was diluted with $\mathrm{H}_{2} \mathrm{O}(10 \mathrm{~mL})$ and poured into a separatory funnel $(125 \mathrm{~mL})$. The organic phase was extracted with $\mathrm{CH}_{2} \mathrm{Cl}_{2}(3 \times 10 \mathrm{~mL})$, dried over $\mathrm{MgSO}_{4}(2 \mathrm{~g})$, filtered and concentrated in vacuo. The crude residue was directly purified by column chromatography $\left(\mathrm{SiO}_{2}, 30 \mathrm{~mm}\right.$ x $45 \mathrm{~cm}, 8: 1$ hexanes/ethyl acetate) to afford the pure product as a light pink oil.

\section{Preparation of $( \pm)-r e l-(4 R, 5 S)$-Dihydro-4-(phenylseleno)-5-phenylfuran-2(3H)-one (2) using HMPA as the Catalyst [WRC-XII-017]}

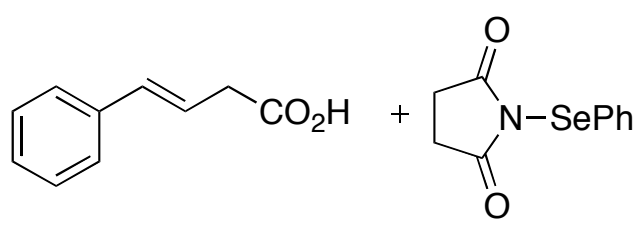

1

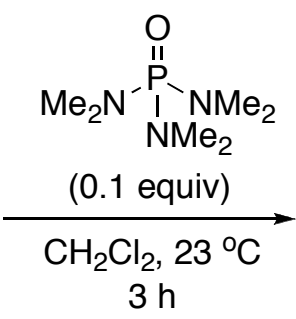

6

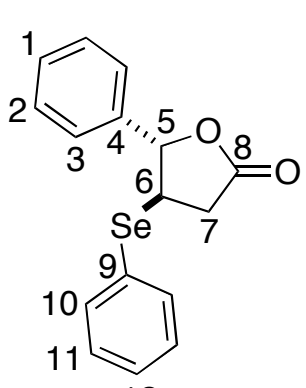

12

2

Following General Procedure II, 5 (304 mg, $1.2 \mathrm{mmol}, 1.2$ equiv) was dissolved in $\mathrm{CH}_{2} \mathrm{Cl}_{2}(5.1 \mathrm{~mL})$. To this was added HMPA (17 $\mu \mathrm{L}, 0.1 \mathrm{mmol}, 0.1$ equiv) and then 1 (162 mg, 1.0 mmol, 1.0 equiv) in $\mathrm{CH}_{2} \mathrm{Cl}_{2}(1.5 \mathrm{~mL})$ over 5 minutes. After $3 \mathrm{~h}$ the clear solution was quenched with a saturated aqueous solution of sodium thiosulfate $(2 \mathrm{~mL})$. The bright yellow biphasic solution was stirred for an additional hour before it was diluted with $\mathrm{H}_{2} \mathrm{O}(10 \mathrm{~mL})$, poured into a separatory funnel and extracted with $\mathrm{CH}_{2} \mathrm{Cl}_{2}(3 \times 10 \mathrm{~mL})$. After drying with 
$\mathrm{MgSO}_{4}(2 \mathrm{~g})$, and filtering the solution was concentrated in vacuo. This was then directly purified by column chromatography $\left(\mathrm{SiO}_{2}, 59 \mathrm{~g}, 30 \mathrm{~mm}\right.$ x $45 \mathrm{~cm}, 8: 1$; then $3: 1$ hexanes/ethyl acetate) to afford $178 \mathrm{mg}(56 \%)$ of $( \pm)-2$.

Data for $( \pm)$-rel-(4R,5S)-dihydro-4-(phenylseleno)-5-phenylfuran-2(3H)-one (2) ${ }^{\mathbf{1}}$ :

$1_{\text {H NMR: }} \quad\left(500 \mathrm{MHz}, \mathrm{CDCl}_{3}\right)$

7.52-7.55 (m, 2 H, CH(10)), 7.35-7.39 (m, 4 H, CH(1,2,12)), 7.28-7.33 (m, $4 \mathrm{H}$, $\mathrm{CH}(3,11)), 5.38(\mathrm{~d}, J=6.9 \mathrm{~Hz}, 1 \mathrm{H}, \mathrm{CH}(5)), 3.76(\mathrm{ddd}, J=8.3,8.3,6.9,1 \mathrm{H}$, $\mathrm{CH}(6)), 3.04\left(\mathrm{dd}, J=18.1,8.3 \mathrm{~Hz}, 1 \mathrm{H}, \mathrm{CH}_{2}(7)\right), 2.68(\mathrm{dd}, J=18.1,8.3 \mathrm{~Hz}, 1 \mathrm{H}$, $\left.\mathrm{CH}_{2}\left(7^{\prime}\right)\right)$

MS: $\quad(\mathrm{EI}+, 70 \mathrm{eV})$

318 (M+1, 40), 255.7 (6), 239.9 (2), 210.9 (2), 183.9 (82), 160 (48), 131 (38), 117 (58), 77 (100), 65 (18)

\section{Preparation of $( \pm)$-rel-(4R,5S)-Dihydro-4-(phenylseleno)-5-phenylfuran-2(3H)-one (2) using} (S)HMPA (8) as the Catalyst [WRC-XII-016]

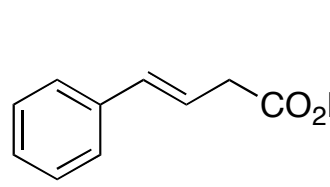

1

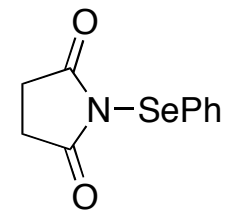

6

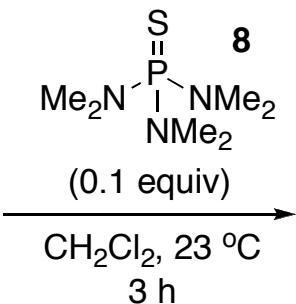

$3 \mathrm{~h}$

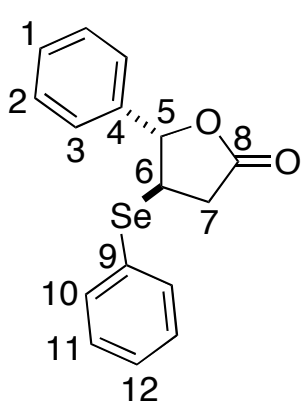

2

Following General Procedure II, 5 (304 mg, $1.2 \mathrm{mmol}, 1.2$ equiv) was dissolved in $\mathrm{CH}_{2} \mathrm{Cl}_{2}(5.1 \mathrm{~mL})$. To this was added (S)HMPA 8 (19.5 mg, $0.1 \mathrm{mmol}, 0.1$ equiv) and then 1 (162 $\mathrm{mg}, 1.0 \mathrm{mmol}, 1.0$ equiv) in $\mathrm{CH}_{2} \mathrm{Cl}_{2}(1.5 \mathrm{~mL})$ over 5 minutes. After $3 \mathrm{~h}$ the dull yellow solution was quenched with a saturated aqueous solution of sodium thiosulfate $(2 \mathrm{~mL})$. The bright yellow biphasic solution was stirred for an additional hour before it was diluted with $\mathrm{H}_{2} \mathrm{O}(10 \mathrm{~mL})$, poured into a separatory funnel and extracted with $\mathrm{CH}_{2} \mathrm{Cl}_{2}(3 \times 10 \mathrm{~mL})$. After drying with $\mathrm{MgSO}_{4}(2 \mathrm{~g})$, and filtering the solution was concentrated in vacuo. This was then directly purified by column chromatography $\left(\mathrm{SiO}_{2}, 60 \mathrm{~g}, 30 \mathrm{~mm}\right.$ x $45 \mathrm{~cm}, 8: 1$; then $3: 1$ hexanes/ethyl acetate) to afford $278 \mathrm{mg}(88 \%)$ of $( \pm)-2$. 
Data for ( \pm )-rel-(4R,5S)-dihydro-4-(phenylseleno)-5-phenylfuran-2(3H)-one (2) ${ }^{1}$ :

$1_{\text {H NMR: }} \quad\left(500 \mathrm{MHz}, \mathrm{CDCl}_{3}\right)$

7.52-7.55 (m, $2 \mathrm{H}, \mathrm{CH}(10))$, 7.35-7.39 (m, $4 \mathrm{H}, \mathrm{CH}(1,2,12)$ ), 7.28-7.33 (m, $4 \mathrm{H}$, $\mathrm{CH}(3,11)), 5.38$ (d, $J=6.9 \mathrm{~Hz}, 1 \mathrm{H}, \mathrm{CH}(5)), 3.76$ (ddd, $J=8.3,8.3,6.9,1 \mathrm{H}$, $\mathrm{CH}(6)), 3.04\left(\mathrm{dd}, J=18.1,8.3 \mathrm{~Hz}, 1 \mathrm{H}, \mathrm{CH}_{2}(7)\right), 2.68$ (dd, $J=18.1,8.3 \mathrm{~Hz}, 1 \mathrm{H}$, $\left.\mathrm{CH}_{2}\left(7^{\prime}\right)\right)$

MS: $\quad(\mathrm{EI}+, 70 \mathrm{eV})$

318 (M+1, 26), 255.7 (1), 239.9 (4), 210.9 (1), 195.1 (68), 183.9 (69), 160 (38), 151 (60), 131 (21), 119.1 (100), 91 (40), 77 (75), 65 (12)

Preparation of $( \pm)$-rel-(4R,5S)-Dihydro-4-(phenylseleno)-5-phenylfuran-2(3H)-one (2) using (Se)HMPA (9) as the Catalyst [WRC-XII-021]

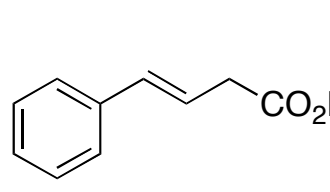

1

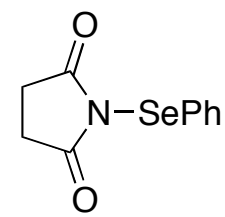

6

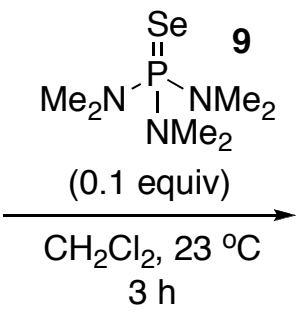

Following General Procedure II, 5 (304 mg, $1.2 \mathrm{mmol}, 1.2$ equiv) was dissolved in $\mathrm{CH}_{2} \mathrm{Cl}_{2}(5.1 \mathrm{~mL})$. To this was added (Se)HMPA 9 (24 mg, $0.1 \mathrm{mmol}, 0.1$ equiv) and then 1 (162 $\mathrm{mg}, 1.0 \mathrm{mmol}, 1.0$ equiv) in $\mathrm{CH}_{2} \mathrm{Cl}_{2}(1.5 \mathrm{~mL})$ over 5 minutes. After $3 \mathrm{~h}$ the bright yellow solution was quenched with a saturated aqueous solution of sodium thiosulfate $(2 \mathrm{~mL})$. The bright yellow biphasic solution was stirred for an additional hour before it was diluted with $\mathrm{H}_{2} \mathrm{O}$ $(10 \mathrm{~mL})$, poured into a separatory funnel and extracted with $\mathrm{CH}_{2} \mathrm{Cl}_{2}(3 \times 10 \mathrm{~mL})$. After drying with $\mathrm{MgSO}_{4}(2 \mathrm{~g})$, and filtering the solution was concentrated in vacuo. This was then directly purified by column chromatography $\left(\mathrm{SiO}_{2}, 61 \mathrm{~g}, 30 \mathrm{~mm}\right.$ x $45 \mathrm{~cm}, 8: 1$; then 3:1 hexanes/ethyl acetate) to afford $300 \mathrm{mg}(95 \%)$ of $( \pm)-2$.

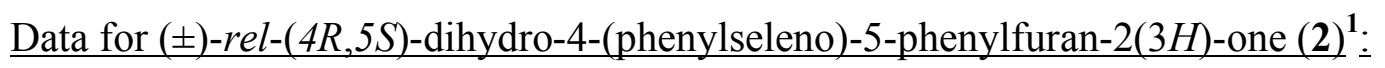

${ }^{1} \underline{\mathrm{H} \mathrm{NMR}}: \quad\left(500 \mathrm{MHz}, \mathrm{CDCl}_{3}\right)$

7.52-7.55 (m, $2 \mathrm{H}, \mathrm{CH}(10))$, 7.35-7.39 (m, $4 \mathrm{H}, \mathrm{CH}(1,2,12))$, 7.28-7.33 (m, $4 \mathrm{H}$, 
$\mathrm{CH}(3,11)), 5.38(\mathrm{~d}, J=6.9 \mathrm{~Hz}, 1 \mathrm{H}, \mathrm{CH}(5)), 3.76(\mathrm{ddd}, J=8.3,8.3,6.9,1 \mathrm{H}$, $\mathrm{CH}(6)), 3.04\left(\mathrm{dd}, J=18.1,8.3 \mathrm{~Hz}, 1 \mathrm{H}, \mathrm{CH}_{2}(7)\right), 2.68(\mathrm{dd}, J=18.1,8.3 \mathrm{~Hz}, 1 \mathrm{H}$, $\left.\mathrm{CH}_{2}\left(7^{\prime}\right)\right)$

MS: $\quad(\mathrm{EI}+, 70 \mathrm{eV})$

317.9 (M+1, 9), 243 (39), 198.9 (12), 183.9 (10), 161 (10), 131 (2), 119 (100), 91

(6), $76(58)$

\section{Preparation of ( \pm )-rel-(4R,5S)-Dihydro-4-(phenylseleno)-5-phenylfuran-2(3H)-one (2) using} Triphenylphosphine Oxide as the Catalyst [WRC-XII-032]

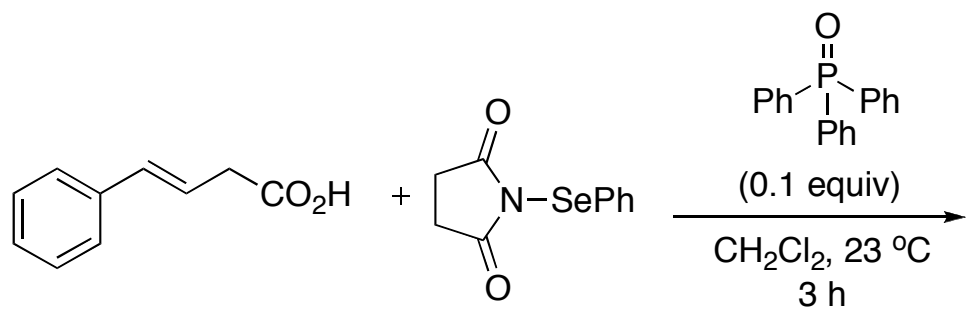

1
6

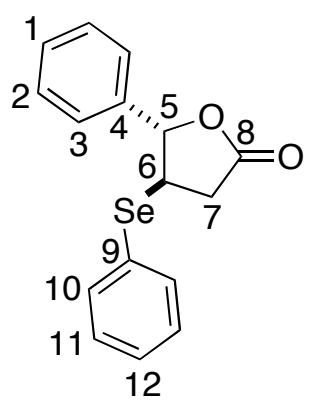

2

Following General Procedure II, 5 (304 mg, $1.2 \mathrm{mmol}, 1.2$ equiv) was dissolved in $\mathrm{CH}_{2} \mathrm{Cl}_{2}(5.1 \mathrm{~mL})$. To this was added triphenylphosphine oxide $(28 \mathrm{mg}, 0.1 \mathrm{mmol}, 0.1$ equiv) and then 1 (162 mg, $1.0 \mathrm{mmol}, 1.0$ equiv) in $\mathrm{CH}_{2} \mathrm{Cl}_{2}(1.5 \mathrm{~mL})$ over 5 minutes. After $3 \mathrm{~h}$ the colorless solution was quenched with a saturated aqueous solution of sodium thiosulfate $(2 \mathrm{~mL})$. The bright yellow biphasic solution was stirred for an additional hour before it was diluted with $\mathrm{H}_{2} \mathrm{O}$ $(10 \mathrm{~mL})$, poured into a separatory funnel and extracted with $\mathrm{CH}_{2} \mathrm{Cl}_{2}(3 \times 10 \mathrm{~mL})$. After drying with $\mathrm{MgSO}_{4}(2 \mathrm{~g})$, and filtering the solution was concentrated in vacuo. This was then directly purified by column chromatography $\left(\mathrm{SiO}_{2}, 55 \mathrm{~g}, 30 \mathrm{~mm}\right.$ x $45 \mathrm{~cm}, 8: 1$; then 3:1 hexanes/ethyl acetate) to afford $16 \mathrm{mg}(6 \%)$ of $( \pm)-2$.

Data for $( \pm)$-rel-(4R,5S)-dihydro-4-(phenylseleno)-5-phenylfuran-2(3H)-one (2) ${ }^{\mathbf{1}}$ :

1슬 $\quad\left(500 \mathrm{MHz}, \mathrm{CDCl}_{3}\right)$

7.52-7.55 (m, 2 H, CH(10)), 7.35-7.39 (m, 4 H, CH(1,2,12)), 7.28-7.33 (m, $4 \mathrm{H}$, $\mathrm{CH}(3,11)), 5.38(\mathrm{~d}, J=6.9 \mathrm{~Hz}, 1 \mathrm{H}, \mathrm{CH}(5)), 3.76(\mathrm{ddd}, J=8.3,8.3,6.9,1 \mathrm{H}$, $\mathrm{CH}(6)), 3.04\left(\mathrm{dd}, J=18.1,8.3 \mathrm{~Hz}, 1 \mathrm{H}, \mathrm{CH}_{2}(7)\right), 2.68(\mathrm{dd}, J=18.1,8.3 \mathrm{~Hz}, 1 \mathrm{H}$, $\left.\mathrm{CH}_{2}\left(7^{\prime}\right)\right)$ 
Preparation of $( \pm)$-rel-(4R,5S)-Dihydro-4-(phenylseleno)-5-phenylfuran-2(3H)-one (2) using Tricyclohexylphosphine oxide as the Catalyst [WRC-XII-036]

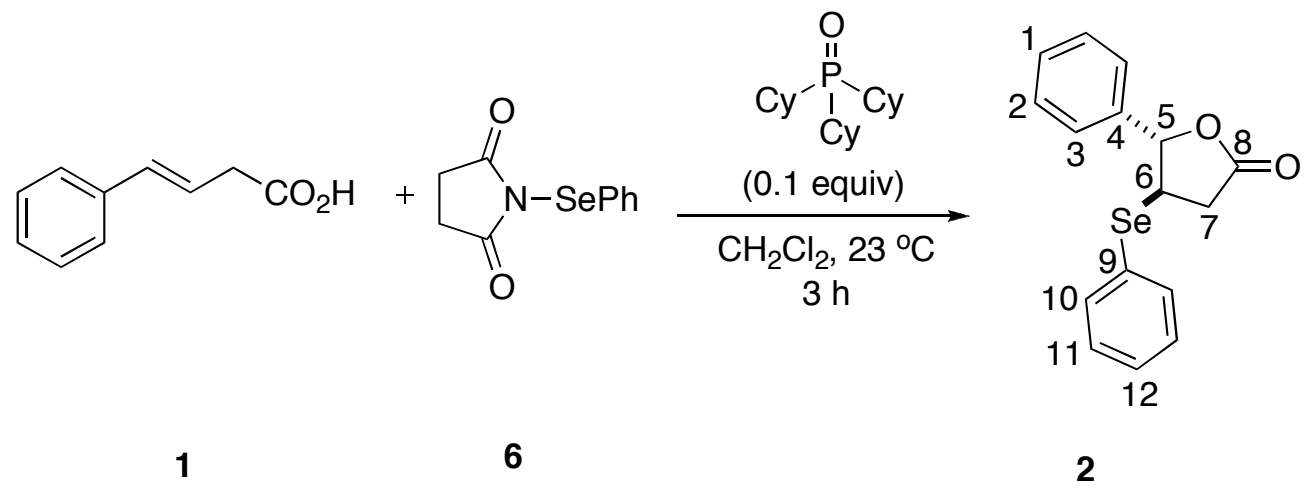

Following General Procedure II, 5 (304 mg, $1.2 \mathrm{mmol}, 1.2$ equiv) was dissolved in $\mathrm{CH}_{2} \mathrm{Cl}_{2}(5.1 \mathrm{~mL})$. To this was added tricyclohexylphosphine oxide (30 mg, $0.1 \mathrm{mmol}, 0.1$ equiv) and then 1 (162 mg, $1.0 \mathrm{mmol}, 1.0$ equiv) in $\mathrm{CH}_{2} \mathrm{Cl}_{2}(1.5 \mathrm{~mL})$ over 5 minutes. After $3 \mathrm{~h}$ the colorless solution was quenched with a saturated aqueous solution of sodium thiosulfate $(2 \mathrm{~mL})$. The bright yellow biphasic solution was stirred for an additional hour before it was diluted with $\mathrm{H}_{2} \mathrm{O}(10 \mathrm{~mL})$, poured into a separatory funnel and extracted with $\mathrm{CH}_{2} \mathrm{Cl}_{2}(3 \mathrm{x} 10 \mathrm{~mL})$. After drying with $\mathrm{MgSO}_{4}(2 \mathrm{~g})$, and filtering the solution was concentrated in vacuo. This was then directly purified by column chromatography $\left(\mathrm{SiO}_{2}, 59 \mathrm{~g}, 30 \mathrm{~mm} \times 45 \mathrm{~cm}, 8: 1\right.$; then $3: 1$ hexanes/ethyl acetate) to afford $63 \mathrm{mg}(20 \%)$ of $( \pm)-2$.

Data for $( \pm)$-rel-(4R,5S)-dihydro-4-(phenylseleno)-5-phenylfuran-2(3H)-one (2) ${ }^{\mathbf{1}}$ :

${ }^{1} \underline{\mathrm{H} \mathrm{NMR}}: \quad\left(500 \mathrm{MHz}, \mathrm{CDCl}_{3}\right)$

7.52-7.55 (m, 2 H, CH(10)), 7.35-7.39 (m, 4 H, CH(1,2,12)), 7.28-7.33 (m, $4 \mathrm{H}$, $\mathrm{CH}(3,11)), 5.38(\mathrm{~d}, J=6.9 \mathrm{~Hz}, 1 \mathrm{H}, \mathrm{CH}(5)), 3.76(\mathrm{ddd}, J=8.3,8.3,6.9,1 \mathrm{H}$, $\mathrm{CH}(6)), 3.04\left(\mathrm{dd}, J=18.1,8.3 \mathrm{~Hz}, 1 \mathrm{H}, \mathrm{CH}_{2}(7)\right), 2.68(\mathrm{dd}, J=18.1,8.3 \mathrm{~Hz}, 1 \mathrm{H}$, $\left.\mathrm{CH}_{2}\left(7^{\prime}\right)\right)$ 
Preparation of $( \pm)$-rel-(4R,5S)-Dihydro-4-(phenylseleno)-5-phenylfuran-2(3H)-one (2) using DMPU as the Catalyst [WRC-XII-039]

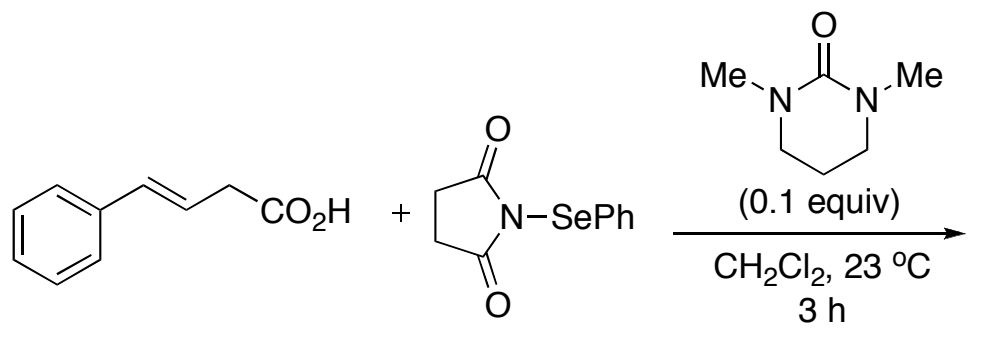

1

6

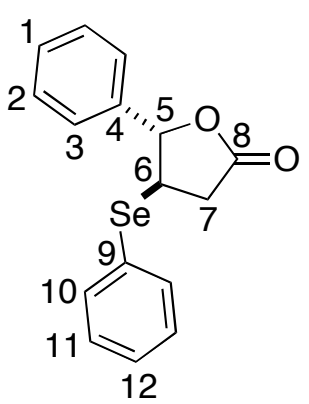

2

Following General Procedure II, 5 (304 mg, $1.2 \mathrm{mmol}, 1.2$ equiv) was dissolved in $\mathrm{CH}_{2} \mathrm{Cl}_{2}(5.1 \mathrm{~mL})$. To this was added DMPU (12 $\mu \mathrm{L}, 0.1 \mathrm{mmol}, 0.1$ equiv) and then 1 (162 $\mathrm{mg}$, $1.0 \mathrm{mmol}, 1.0$ equiv) in $\mathrm{CH}_{2} \mathrm{Cl}_{2}(1.5 \mathrm{~mL})$ over 5 minutes. After $3 \mathrm{~h}$ the colorless solution was quenched with a saturated aqueous solution of sodium thiosulfate $(2 \mathrm{~mL})$. The bright yellow biphasic solution was stirred for an additional hour before it was diluted with $\mathrm{H}_{2} \mathrm{O}(10 \mathrm{~mL})$, poured into a separatory funnel and extracted with $\mathrm{CH}_{2} \mathrm{Cl}_{2}(3 \times 10 \mathrm{~mL})$. After drying with $\mathrm{MgSO}_{4}(2 \mathrm{~g})$, and filtering the solution was concentrated in vacuo. This was then directly purified by column chromatography $\left(\mathrm{SiO}_{2}, 62 \mathrm{~g}, 30 \mathrm{~mm}\right.$ x $45 \mathrm{~cm}, 8: 1$; then 3:1 hexanes/ethyl acetate) to afford $160 \mathrm{mg}(51 \%)$ of $( \pm)-2$.

Data for $( \pm)$-rel-(4R,5S)-dihydro-4-(phenylseleno)-5-phenylfuran-2(3H)-one (2) ${ }^{1}$ :

${ }^{1} \underline{\text { H NMR: }} \quad\left(500 \mathrm{MHz}, \mathrm{CDCl}_{3}\right)$

7.52-7.55 (m, $2 \mathrm{H}, \mathrm{CH}(10))$, 7.35-7.39 (m, $4 \mathrm{H}, \mathrm{CH}(1,2,12))$, 7.28-7.33 (m, $4 \mathrm{H}$, $\mathrm{CH}(3,11)), 5.38(\mathrm{~d}, J=6.9 \mathrm{~Hz}, 1 \mathrm{H}, \mathrm{CH}(5)), 3.76(\mathrm{ddd}, J=8.3,8.3,6.9,1 \mathrm{H}$, $\mathrm{CH}(6)), 3.04\left(\mathrm{dd}, J=18.1,8.3 \mathrm{~Hz}, 1 \mathrm{H}, \mathrm{CH}_{2}(7)\right), 2.68(\mathrm{dd}, J=18.1,8.3 \mathrm{~Hz}, 1 \mathrm{H}$, $\left.\mathrm{CH}_{2}\left(7^{\prime}\right)\right)$ 
Preparation of $( \pm)-r e l-(4 R, 5 S)$-Dihydro-4-(phenylseleno)-5-phenylfuran-2(3H)-one (2) using Triphenylphosphine Sulfide as the Catalyst [WRC-XII-031]

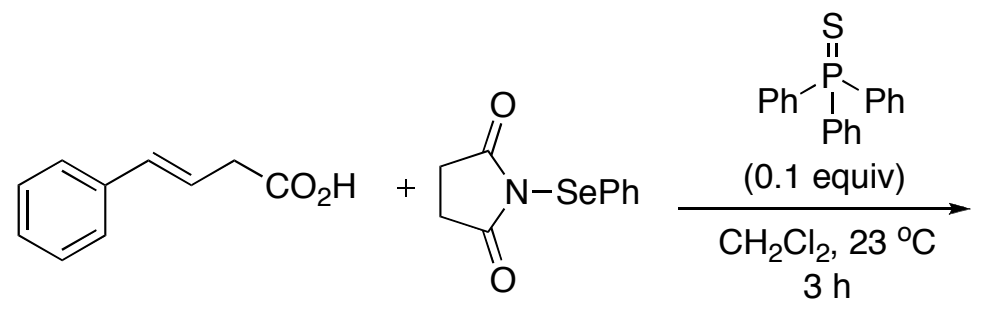

1
6

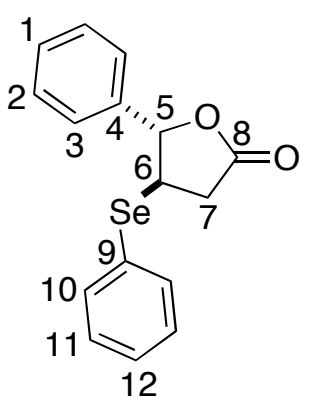

2

Following General Procedure II, 5 (304 mg, $1.2 \mathrm{mmol}, 1.2$ equiv) was dissolved in $\mathrm{CH}_{2} \mathrm{Cl}_{2}(5.1 \mathrm{~mL})$. To this was added triphenylphosphine sulfide (29 mg, $0.1 \mathrm{mmol}, 0.1$ equiv) and then 1 (162 mg, $1.0 \mathrm{mmol}, 1.0$ equiv) in $\mathrm{CH}_{2} \mathrm{Cl}_{2}(1.5 \mathrm{~mL})$ over 5 minutes. After $3 \mathrm{~h}$ the yellow solution was quenched with a saturated aqueous solution of sodium thiosulfate $(2 \mathrm{~mL})$. The bright yellow biphasic solution was stirred for an additional hour before it was diluted with $\mathrm{H}_{2} \mathrm{O}(10 \mathrm{~mL})$, poured into a separatory funnel and extracted with $\mathrm{CH}_{2} \mathrm{Cl}_{2}(3 \mathrm{x} 10 \mathrm{~mL})$. After drying with $\mathrm{MgSO}_{4}(2 \mathrm{~g})$, and filtering the solution was concentrated in vacuo. This was then directly purified by column chromatography $\left(\mathrm{SiO}_{2}, 66 \mathrm{~g}, 30 \mathrm{~mm}\right.$ x $45 \mathrm{~cm}, 8: 1$; then $3: 1$ hexanes/ethyl acetate) to afford $295 \mathrm{mg}(94 \%)$ of ( \pm )-2.

Data for $( \pm)$-rel-(4R,5S)-dihydro-4-(phenylseleno)-5-phenylfuran-2(3H)-one (2) ${ }^{\mathbf{1}}$ :

${ }^{1} \underline{\text { H NMR: }} \quad\left(500 \mathrm{MHz}, \mathrm{CDCl}_{3}\right)$

7.52-7.55 (m, 2 H, CH(10)), 7.35-7.39 (m, 4 H, CH(1,2,12)), 7.28-7.33 (m, 4 H, $\mathrm{CH}(3,11)), 5.38(\mathrm{~d}, J=6.9 \mathrm{~Hz}, 1 \mathrm{H}, \mathrm{CH}(5)), 3.76(\mathrm{ddd}, J=8.3,8.3,6.9,1 \mathrm{H}$, $\mathrm{CH}(6)), 3.04\left(\mathrm{dd}, J=18.1,8.3 \mathrm{~Hz}, 1 \mathrm{H}, \mathrm{CH}_{2}(7)\right), 2.68(\mathrm{dd}, J=18.1,8.3 \mathrm{~Hz}, 1 \mathrm{H}$, $\left.\mathrm{CH}_{2}\left(7^{\prime}\right)\right)$ 
Preparation of $( \pm)$-rel-(4R,5S)-Dihydro-4-(phenylseleno)-5-phenylfuran-2(3H)-one (2) using Tricyclohexylphosphine Sulfide as the Catalyst [WRC-XII-035]

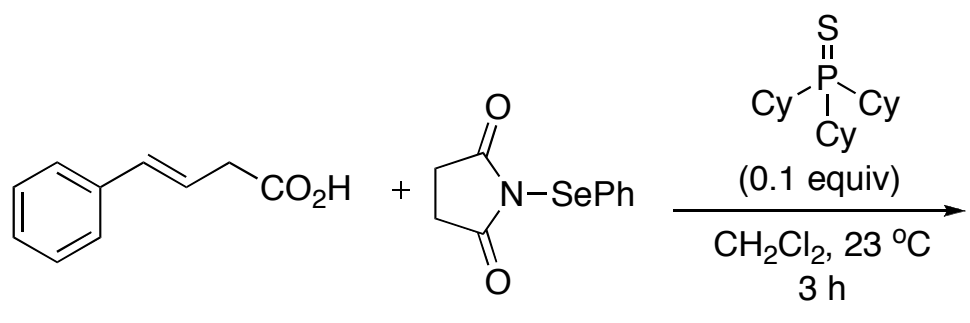

1

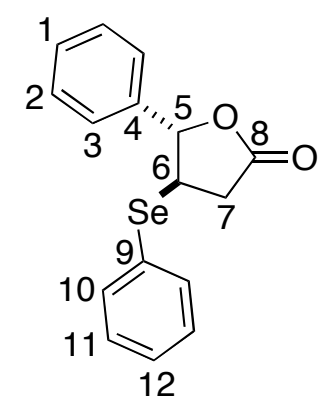

2

Following General Procedure II, 5 (304 mg, $1.2 \mathrm{mmol}, 1.2$ equiv) was dissolved in $\mathrm{CH}_{2} \mathrm{Cl}_{2}(5.1 \mathrm{~mL})$. To this was added tricyclohexylphosphine sulfide $(31 \mathrm{mg}, 0.1 \mathrm{mmol}, 0.1$ equiv) and then 1 (162 mg, $1.0 \mathrm{mmol}, 1.0$ equiv) in $\mathrm{CH}_{2} \mathrm{Cl}_{2}(1.5 \mathrm{~mL})$ over 5 minutes. After $3 \mathrm{~h}$ the yellow solution was quenched with a saturated aqueous solution of sodium thiosulfate (2 $\mathrm{mL})$. The bright yellow biphasic solution was stirred for an additional hour before it was diluted with $\mathrm{H}_{2} \mathrm{O}(10 \mathrm{~mL})$, poured into a separatory funnel and extracted with $\mathrm{CH}_{2} \mathrm{Cl}_{2}(3 \times 10 \mathrm{~mL})$. After drying with $\mathrm{MgSO}_{4}(2 \mathrm{~g})$, and filtering the solution was concentrated in vacuo. This was then directly purified by column chromatography $\left(\mathrm{SiO}_{2}, 67 \mathrm{~g}, 30 \mathrm{~mm}\right.$ x $45 \mathrm{~cm}, 8: 1$; then $3: 1$ hexanes/ethyl acetate) to afford $277 \mathrm{mg}(88 \%)$ of $( \pm)-\mathbf{2}$.

Data for $( \pm)$-rel-(4R,5S)-dihydro-4-(phenylseleno)-5-phenylfuran-2(3H)-one (2) ${ }^{1}$ :

${ }^{1} \underline{\text { H NMR: }} \quad\left(500 \mathrm{MHz}, \mathrm{CDCl}_{3}\right)$

7.52-7.55 (m, 2 H, CH(10)), 7.35-7.39 (m, 4 H, CH(1,2,12)), 7.28-7.33 (m, $4 \mathrm{H}$, $\mathrm{CH}(3,11)), 5.38$ (d, $J=6.9 \mathrm{~Hz}, 1 \mathrm{H}, \mathrm{CH}(5)), 3.76$ (ddd, $J=8.3,8.3,6.9,1 \mathrm{H}$, $\mathrm{CH}(6)), 3.04\left(\mathrm{dd}, J=18.1,8.3 \mathrm{~Hz}, 1 \mathrm{H}, \mathrm{CH}_{2}(7)\right), 2.68(\mathrm{dd}, J=18.1,8.3 \mathrm{~Hz}, 1 \mathrm{H}$, $\left.\mathrm{CH}_{2}\left(7^{\prime}\right)\right)$ 
Preparation of $( \pm)$-rel-(4R,5S)-Dihydro-4-(phenylseleno)-5-phenylfuran-2(3H)-one (2) using 1,3-Dimethylhexahydropyrimidine-2-thione as the Catalyst [WRC-XII-041]

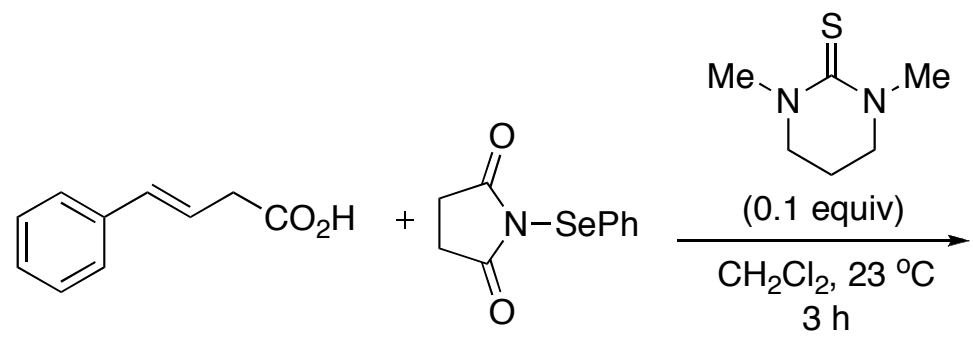

1

6

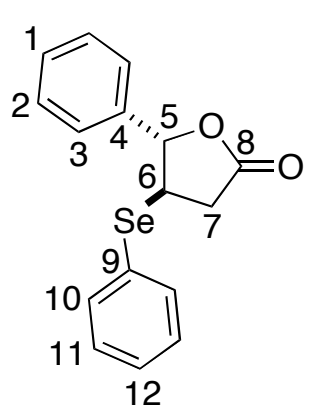

2

Following General Procedure II, 5 (304 mg, $1.2 \mathrm{mmol}, 1.2$ equiv) was dissolved in $\mathrm{CH}_{2} \mathrm{Cl}_{2}(5.1 \mathrm{~mL})$. To this was added 1,3-dimethylhexahydropyrimidine-2-thione (14 $\mathrm{mg}, 0.1$ mmol, 0.1 equiv) and then 1 (162 mg, $1.0 \mathrm{mmol}, 1.0$ equiv) in $\mathrm{CH}_{2} \mathrm{Cl}_{2}$ (1.5 mL) over 5 minutes. After $3 \mathrm{~h}$ the yellow solution was quenched with a saturated aqueous solution of sodium thiosulfate $(2 \mathrm{~mL})$. The bright yellow biphasic solution was stirred for an additional hour before it was diluted with $\mathrm{H}_{2} \mathrm{O}(10 \mathrm{~mL})$, poured into a separatory funnel and extracted with $\mathrm{CH}_{2} \mathrm{Cl}_{2}(3 \mathrm{x}$ $10 \mathrm{~mL})$. After drying with $\mathrm{MgSO}_{4}(2 \mathrm{~g})$, and filtering the solution was concentrated in vacuo. This was then directly purified by column chromatography $\left(\mathrm{SiO}_{2}, 66 \mathrm{~g}, 30 \mathrm{~mm}\right.$ x $45 \mathrm{~cm}, 8: 1$; then $3: 1$ hexanes/ethyl acetate) to afford $275 \mathrm{mg}(87 \%)$ of $( \pm)-2$.

Data for $( \pm)$-rel-(4R,5S)-dihydro-4-(phenylseleno)-5-phenylfuran-2(3H)-one $(\mathbf{2})^{\mathbf{1}}:$

${ }^{1}$ H NMR: $\quad\left(500 \mathrm{MHz}, \mathrm{CDCl}_{3}\right)$

7.52-7.55 (m, 2 H, CH(10)), 7.35-7.39 (m, 4 H, CH(1,2,12)), 7.28-7.33 (m, $4 \mathrm{H}$, $\mathrm{CH}(3,11)), 5.38(\mathrm{~d}, J=6.9 \mathrm{~Hz}, 1 \mathrm{H}, \mathrm{CH}(5)), 3.76(\mathrm{ddd}, J=8.3,8.3,6.9,1 \mathrm{H}$, $\mathrm{CH}(6)), 3.04\left(\mathrm{dd}, J=18.1,8.3 \mathrm{~Hz}, 1 \mathrm{H}, \mathrm{CH}_{2}(7)\right), 2.68(\mathrm{dd}, J=18.1,8.3 \mathrm{~Hz}, 1 \mathrm{H}$, $\left.\mathrm{CH}_{2}\left(7^{\prime}\right)\right)$ 
Preparation of $( \pm)$-rel-(4R,5S)-Dihydro-4-(phenylseleno)-5-phenylfuran-2(3H)-one (2) using Hexamethylphosphorous Triamide as the catalyst [WRC-XII-041]

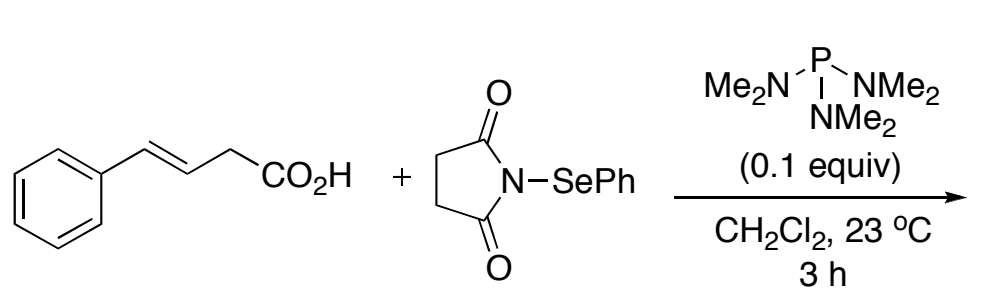

1

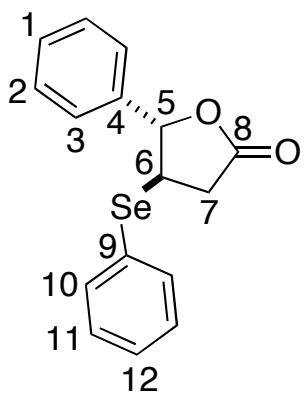

6

2

Following General Procedure II, 5 (304 mg, $1.2 \mathrm{mmol}, 1.2$ equiv) was dissolved in $\mathrm{CH}_{2} \mathrm{Cl}_{2}(5.1 \mathrm{~mL})$. To this was added hexamethylphosphorous triamide (17 $\mu \mathrm{L}, 0.1 \mathrm{mmol}, 0.1$ equiv) and then 1 (162 mg, $1.0 \mathrm{mmol}, 1.0$ equiv) in $\mathrm{CH}_{2} \mathrm{Cl}_{2}(1.5 \mathrm{~mL})$ over 5 minutes. After $3 \mathrm{~h}$ the bright yellow solution was quenched with a saturated aqueous solution of sodium thiosulfate $(2 \mathrm{~mL})$. The bright yellow biphasic solution was stirred for an additional hour before it was diluted with $\mathrm{H}_{2} \mathrm{O}(10 \mathrm{~mL})$, poured into a separatory funnel and extracted with $\mathrm{CH}_{2} \mathrm{Cl}_{2}(3 \times 10$ $\mathrm{mL})$. After drying with $\mathrm{MgSO}_{4}(2 \mathrm{~g})$, and filtering the solution was concentrated in vacuo. This was then directly purified by column chromatography $\left(\mathrm{SiO}_{2}, 56 \mathrm{~g}, 30 \mathrm{~mm}\right.$ x $45 \mathrm{~cm}$, 8:1; then 3:1 hexanes/ethyl acetate) to afford $292 \mathrm{mg}(92 \%)$ of $( \pm)-\mathbf{2}$.

Data for $( \pm)$-rel-(4R,5S)-dihydro-4-(phenylseleno)-5-phenylfuran-2(3H)-one (2) ${ }^{\mathbf{1}}$ :

${ }^{1} \underline{\text { H NMR: }} \quad\left(500 \mathrm{MHz}, \mathrm{CDCl}_{3}\right)$

7.52-7.55 (m, 2 H, CH(10)), 7.35-7.39 (m, 4 H, CH(1,2,12)), 7.28-7.33 (m, 4 H, $\mathrm{CH}(3,11)), 5.38(\mathrm{~d}, J=6.9 \mathrm{~Hz}, 1 \mathrm{H}, \mathrm{CH}(5)), 3.76(\mathrm{ddd}, J=8.3,8.3,6.9,1 \mathrm{H}$, $\mathrm{CH}(6)), 3.04\left(\mathrm{dd}, J=18.1,8.3 \mathrm{~Hz}, 1 \mathrm{H}, \mathrm{CH}_{2}(7)\right), 2.68(\mathrm{dd}, J=18.1,8.3 \mathrm{~Hz}, 1 \mathrm{H}$, $\left.\mathrm{CH}_{2}\left(7^{\prime}\right)\right)$ 


\section{React-IR Rate Data:}

\section{React-IR Experiment with $N$-Phenylselenylsuccinimide (6) and (E)-4-Phenyl-3-butenoic acid (1) [WRC-IX-061]}

An oven-dried 3-necked, React-IR cell containing a stir bar was brought into the dry box to cool. The cell was charged with $N$-phenylselenylsuccinimide 6 (76.2 $\mathrm{mg}, 0.3 \mathrm{mmol}, 1.0$ equiv). The cell was then removed from the box, connected to the React-IR probe and fitted with two septa and an argon inlet adaptor. The apparatus was maintained under a static atmosphere of argon pressure for the duration of the experiment. Dichloromethane $(1.6 \mathrm{~mL})$ was added to the cell and with stirring and the background was scanned $\left(1650-1850 \mathrm{~cm}^{-1}\right.$ range). Scanning was then commenced (1650-1850 $\mathrm{cm}^{-1}$ range, $16 \mathrm{~cm}^{-1}$ resolution, 64 scans per minute) and after a 3min delay a solution of acid 1 (49 $\mathrm{mg}, 0.3 \mathrm{mmol}, 1.0$ equiv) in $\mathrm{CH}_{2} \mathrm{Cl}_{2}(0.4 \mathrm{~mL})$ was added rapidly via syringe. The yellow solution was stirred for $6 \mathrm{~h}$ during which the intensity of the lactone product peak $\left(1785 \mathrm{~cm}^{-1}\right)$ was monitored.

IR Data:

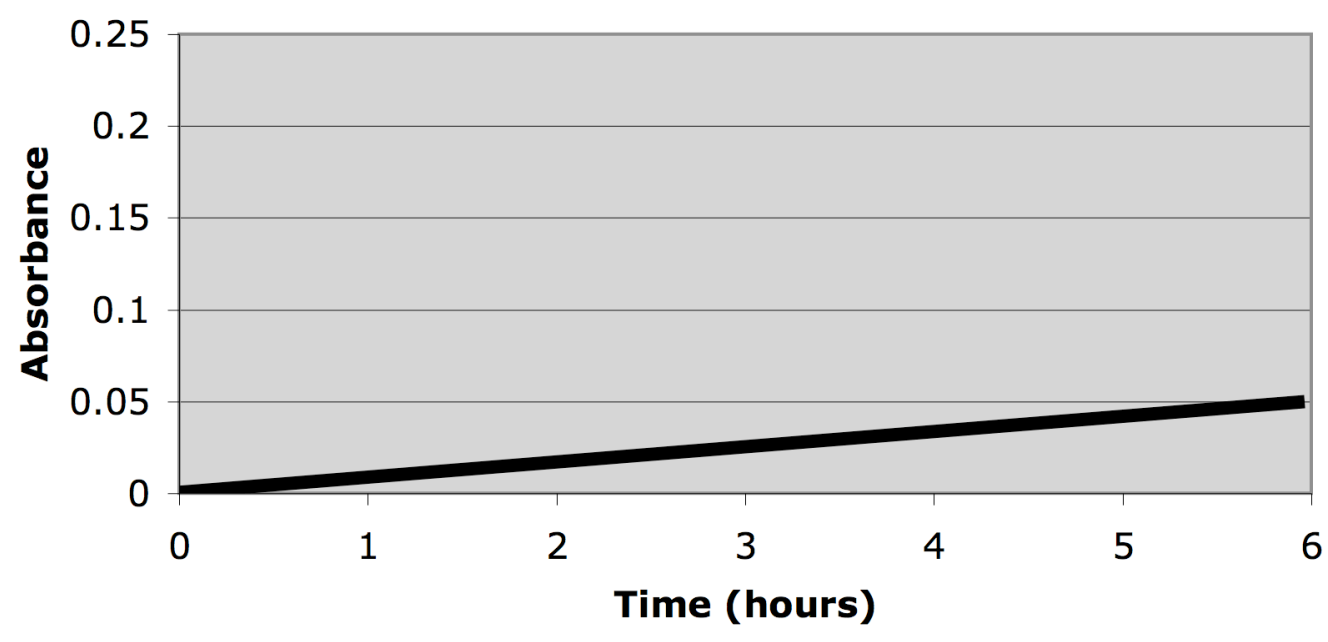




\section{React-IR Experiment with $N$-Phenylselenylsuccinimide (6), (E)-4-Phenyl-3-butenoic acid (1), and HMPA [WRC-IX-090]}

An oven-dried, 3-necked React-IR cell containing a stir bar was brought into the dry box to cool. The cell was charged with $N$-phenylselenylsuccinimide 6 (50 mg, 0.2 mmol, 1.1 equiv). The cell was then removed from the box, connected to the React-IR probe and fitted with two septa and an argon inlet adaptor. The apparatus was maintained under a static atmosphere of argon pressure for the duration of the experiment. Dichloromethane (1.0 mL) and then HMPA (2 $\mu \mathrm{L}, 0.01 \mathrm{mmol}, 0.05$ equiv) were added to the cell and while stirring, the background was scanned $\left(1650-1850 \mathrm{~cm}^{-1}\right.$ range). Scanning was then commenced $\left(1650-1850 \mathrm{~cm}^{-1}\right.$ range, 16 $\mathrm{cm}^{-1}$ resolution, 64 scans per minute) and after a 3-min delay a solution of acid 1 (32 $\mathrm{mg}, 0.2$ mmol, 1.0 equiv) in $\mathrm{CH}_{2} \mathrm{Cl}_{2}(0.35 \mathrm{~mL})$ was added rapidly via syringe. The yellow solution was stirred for $6 \mathrm{~h}$ during which the intensity of the lactone product peak $\left(1785 \mathrm{~cm}^{-1}\right)$ was monitored. IR Data:

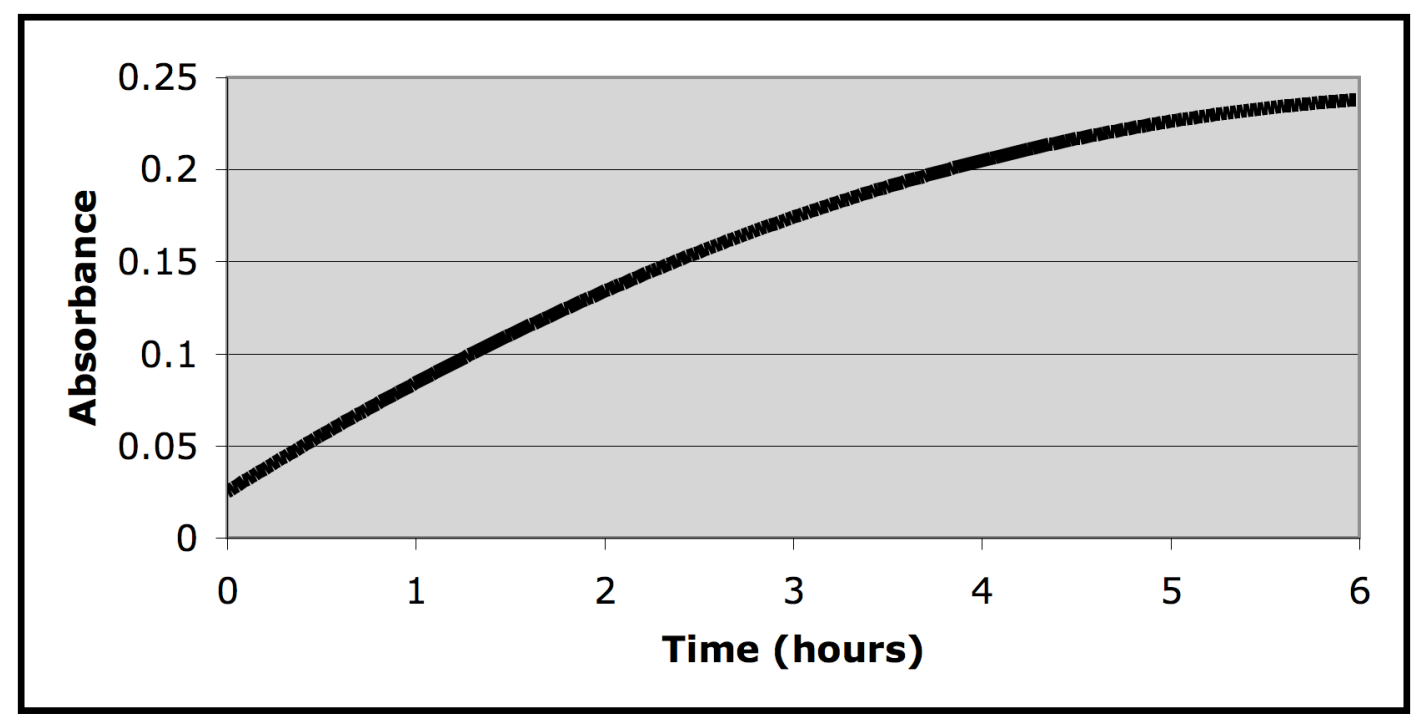




\section{React-IR Experiment with $N$-Phenylselenylsuccinimide (6), (E)-4-Phenyl-3-butenoic acid (1), and (S)HMPA (8) [WRC-IX-060]}

An oven-dried, 3-necked React-IR cell containing a stir bar was brought into the dry box to cool. The cell was charged with $N$-phenylselenylsuccinimide 6 (76 mg, 0.3 mmol, 1.0 equiv) and thiophosphoramide 8 ( $3 \mathrm{mg}, 0.015 \mathrm{mmol}, 0.05$ equiv). The cell was then removed from the box, connected to the React-IR probe and fitted with two septa and an argon inlet adaptor. The apparatus was maintained under a static atmosphere of argon pressure for the duration of the experiment. Dichloromethane $(1.6 \mathrm{~mL})$ was added to the cell and with stirring and the background was scanned $\left(1650-1850 \mathrm{~cm}^{-1}\right.$ range). Scanning was then commenced (1650-1850 $\mathrm{cm}^{-1}$ range, $16 \mathrm{~cm}^{-1}$ resolution, 64 scans per minute) and after a 3-min delay a solution of acid 1 (49 $\mathrm{mg}, 0.3 \mathrm{mmol}, 1.0$ equiv) in $\mathrm{CH}_{2} \mathrm{Cl}_{2}(0.4 \mathrm{~mL})$ was added rapidly via syringe. The yellow solution was stirred for $3 \mathrm{~h}$ during which the intensity of the lactone product peak $\left(1785 \mathrm{~cm}^{-1}\right)$ was monitored.

IR Data:

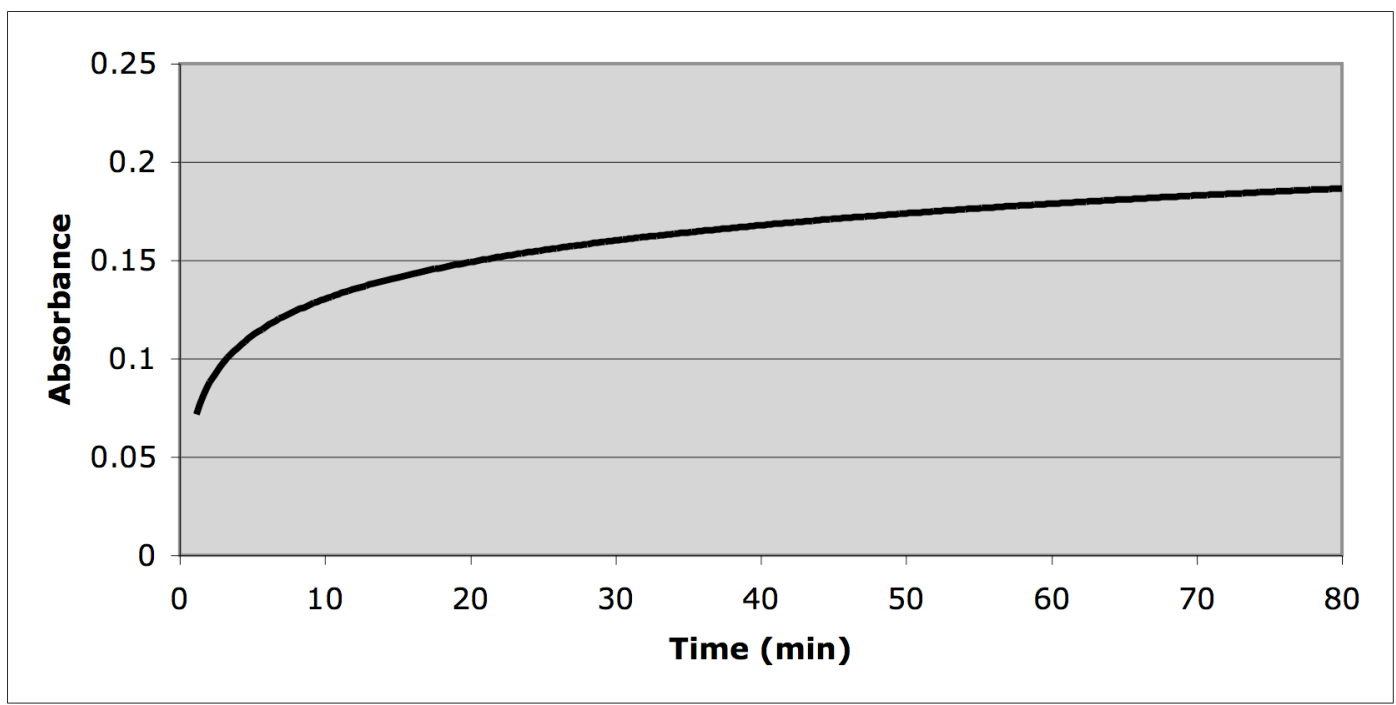




\section{React-IR Experiment with $N$-Phenylselenylsuccinimide (6), $(E)-4$-Phenyl-3-butenoic acid}

\section{(1), and (Se)HMPA (9) [WRC-IX-083]}

An oven-dried, 3-necked React-IR cell containing a stir bar was brought into the dry box to cool. The cell was charged with $N$-phenylselenylsuccinimide 6 (50 mg, 0.2 mmol, 1.0 equiv) and selenophosphoramide 9 ( $2 \mathrm{mg}, 0.01 \mathrm{mmol}, 0.05$ equiv). The cell was then removed from the box, connected to the React-IR probe and fitted with two septa and an argon inlet adaptor. The apparatus was maintained under a static atmosphere of argon pressure for the duration of the experiment. Dichloromethane $(1.0 \mathrm{~mL})$ was added to the cell and with stirring and the background was scanned $\left(1650-1850 \mathrm{~cm}^{-1}\right.$ range). Scanning was then commenced (1650-1850 $\mathrm{cm}^{-1}$ range, $16 \mathrm{~cm}^{-1}$ resolution, 64 scans per minute) and after a 3-min delay a solution of acid 1 (32 mg, $0.2 \mathrm{mmol}, 1.0$ equiv) in $\mathrm{CH}_{2} \mathrm{Cl}_{2}(0.35 \mathrm{~mL}$ ) was added rapidly via syringe. The yellow solution was stirred for 35 minutes during which the intensity of the lactone product peak (1785 $\mathrm{cm}^{-1}$ ) was monitored.

IR Data:

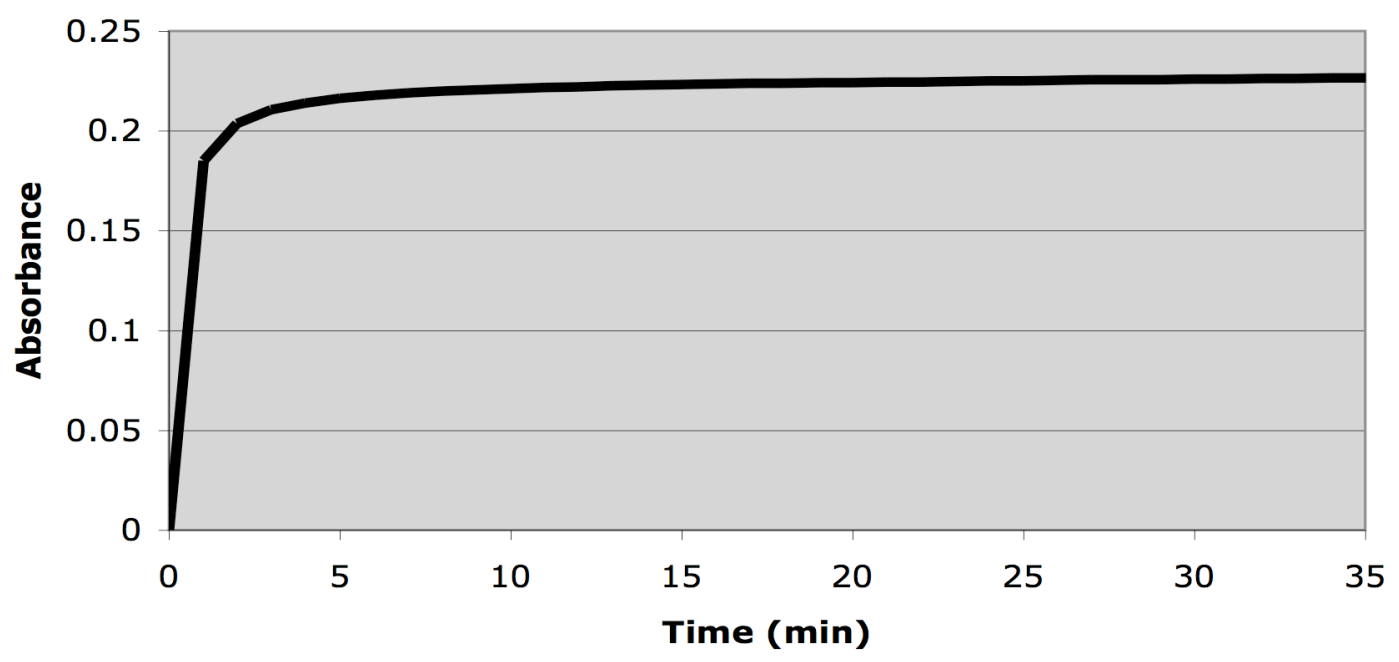




\section{Mechanistic Studies:}

\section{Preparation of Hexamethylphosphorous Triamide $-N$-Phenylselenylsuccinimide Complex} (13) [WRC-XIII-062]

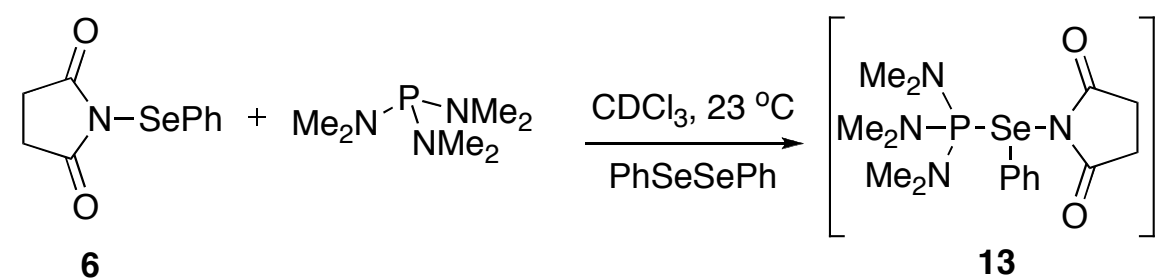

An oven dried NMR tube was cooled in the dry box, charged with $N$-phenylselenylsuccinimide 6 (127 mg, $0.5 \mathrm{mmol}, 1$ equiv) and Diphenyl diselenide (50 $\mathrm{mg}$, as an internal standard: $462 \mathrm{ppm}$ ), and sealed with a rubber NMR septum. After removal from the dry box $\mathrm{CDCl}_{3}(1.5 \mathrm{~mL})$ was added via syringe and the tube vortexed for 30 seconds to insure homogeneity. HMPT (91 $\mu \mathrm{L}, 0.5 \mathrm{mmol}, 1$ equiv) was added and the tube was immediately inserted into the NMR spectrometer.

Data for HMPT-NPSS Complex (13):

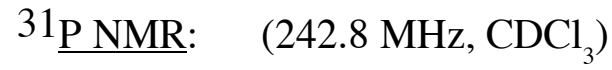

$$
60.23(\mathrm{~d}, J=488 \mathrm{~Hz}), 35.62,25.54,18.26
$$

77 Se NMR: $\quad\left(114.4 \mathrm{MHz}, \mathrm{CDCl}_{3}\right)$

$$
716.11,462.24,290.43(\mathrm{~d}, J=488 \mathrm{~Hz})
$$

Note: In both the ${ }^{31} \mathrm{P}$ NMR as well as the ${ }^{77}$ Se NMR experiments there were small but consistent uncoupled signals in addition to the P-Se complex 13. Attempts thus far at isolating any of these species for further spectroscopic study hás not proved fruitful. 


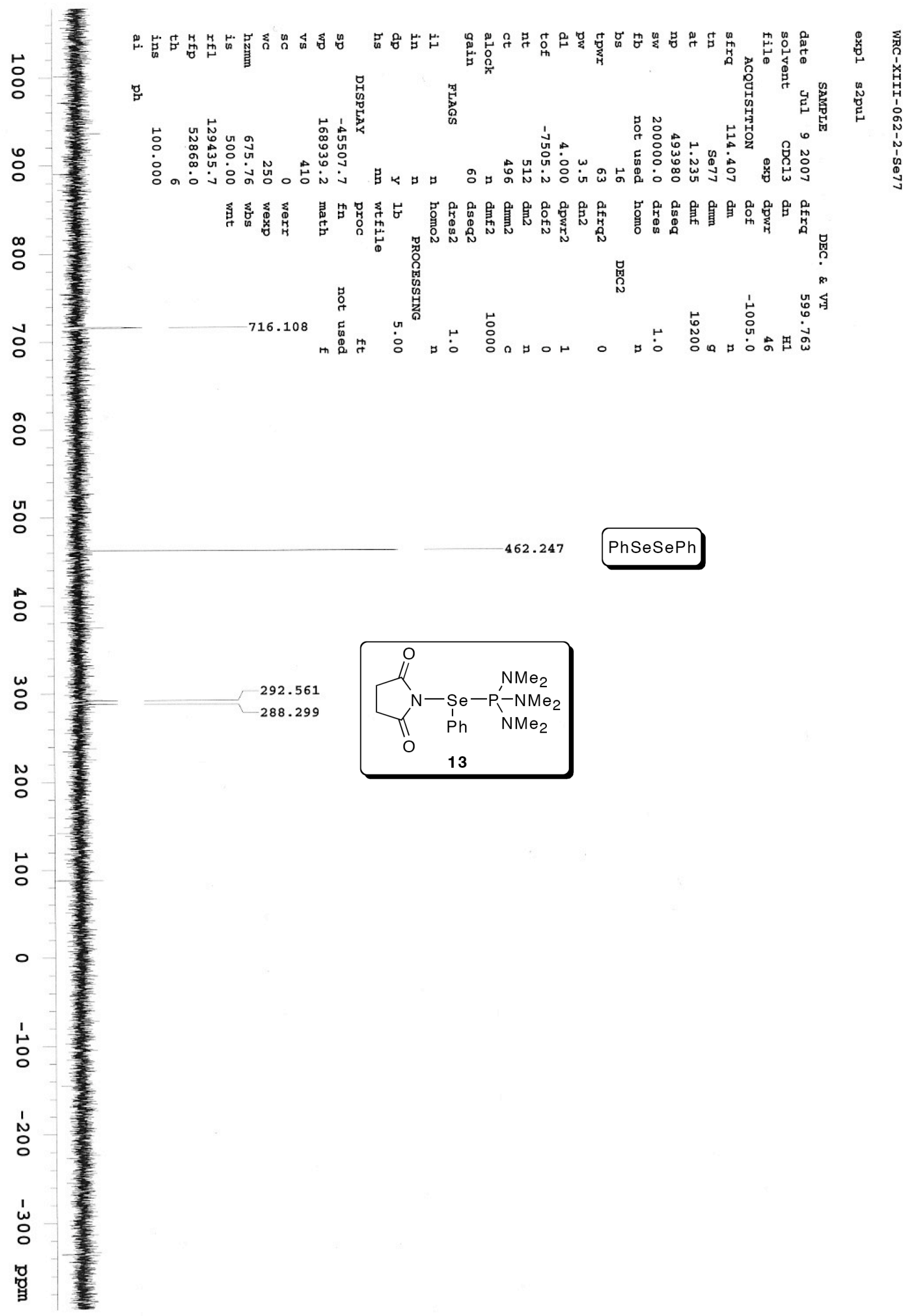




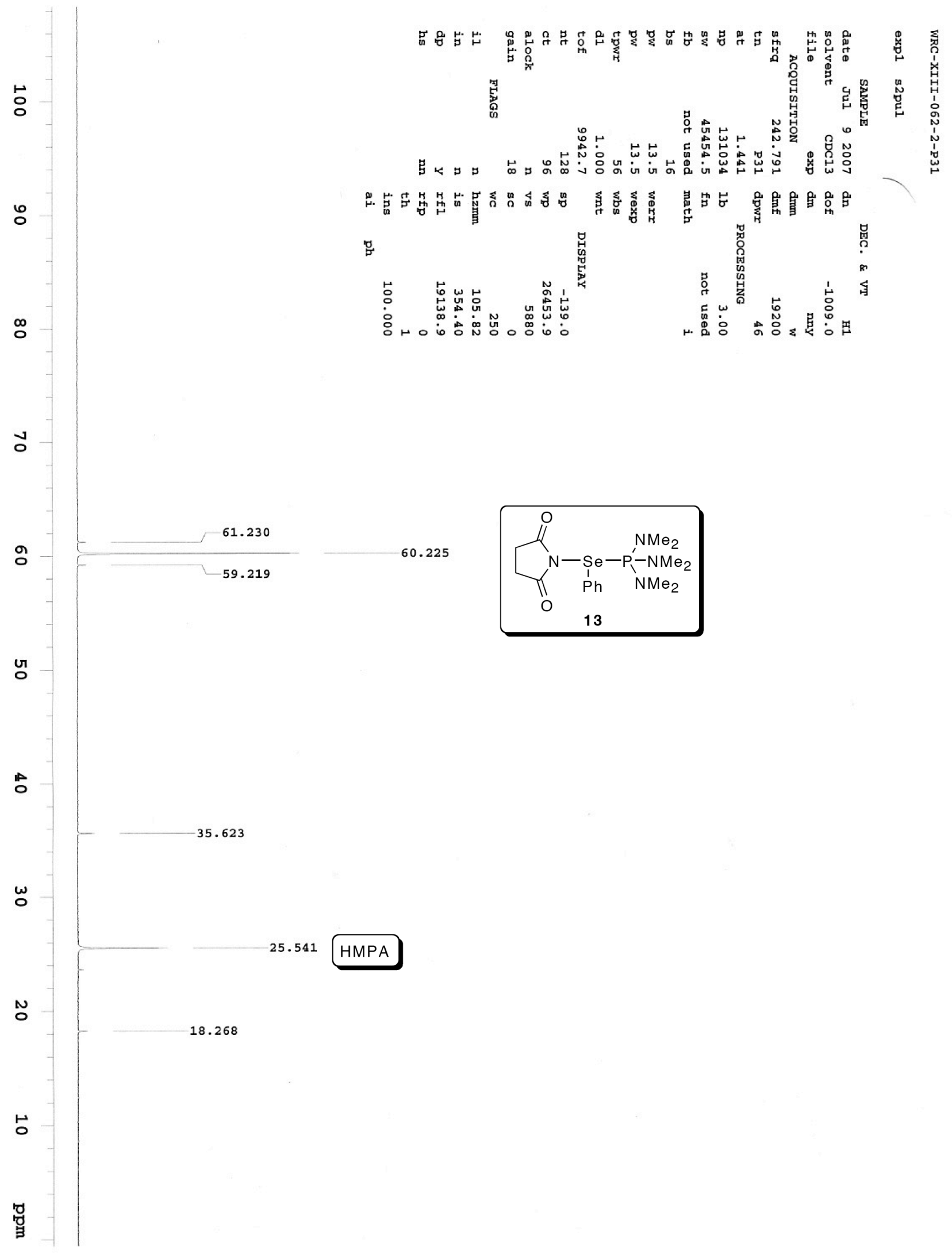


Preparation of $( \pm)-r e l-(4 R, 5 S)$-Dihydro-4-(phenylseleno)-5-phenylfuran-2(3H)-one $(2)$ from Trimethylsilyl Ester (15), NPSS (6) and Acetic acid [WRC-XII-054]

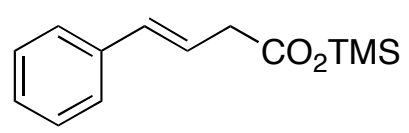

15

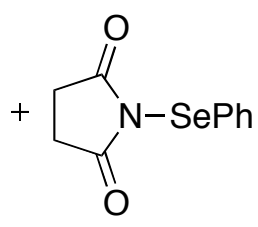

6

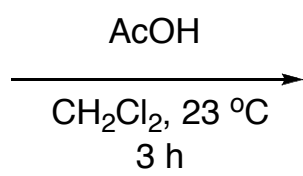

To a flame-dried, $25 \mathrm{~mL}$ Schlenk flask equipped with a stir bar under argon was added the $N$-phenylselenylsuccinimide 6 (304 mg, $1.2 \mathrm{mmol}, 1.2$ equiv) in the dry box. After removal from the dry box and reattachment of the flask to a manifold, 6 was diluted with $\mathrm{CH}_{2} \mathrm{Cl}_{2}(8 \mathrm{~mL})$. To the colorless solution was added a solution of $(E)$-trimethylsilyl-4-phenyl-3-butenoate 15 (234 mg, $1.0 \mathrm{mmol}, 1.0$ equiv), and $\mathrm{AcOH}$ (57 $\mu \mathrm{L}, 1.0 \mathrm{mmol}, 1.0$ equiv) in $\mathrm{CH}_{2} \mathrm{Cl}_{2}$ (2 mL) drop wise over 5 minutes. After $3 \mathrm{~h}$ a saturated aqueous solution of sodium thiosulfate $(5 \mathrm{~mL})$ was added directly to the reaction mixture to quench the remaining 6 . The biphasic solution was rapidly stirred for an additional $1 \mathrm{~h}$, after which the solution was diluted with $\mathrm{H}_{2} \mathrm{O}(20 \mathrm{~mL})$ and poured into a separatory funnel $(125 \mathrm{~mL})$. The organic phase was extracted with $\mathrm{CH}_{2} \mathrm{Cl}_{2}(3 \times 20$ $\mathrm{mL}$ ), dried over $\mathrm{MgSO}_{4}(3 \mathrm{~g})$, filtered and concentrated in vacuo. The crude residue was directly purified by column chromatography $\left(\mathrm{SiO}_{2}, 79 \mathrm{~g}, 30 \mathrm{~mm}\right.$ x $45 \mathrm{~cm}, 8: 1$ hexanes/ethyl acetate) to afford $41 \mathrm{mg}(13 \%)$ of the pure product $( \pm)-2$.

Data for $( \pm)$-rel-(4R,5S)-dihydro-4-(phenylseleno)-5-phenylfuran-2(3H)-one (2) ${ }^{\mathbf{1}}$ :

${ }^{1} \underline{\text { H NMR: }} \quad\left(500 \mathrm{MHz}, \mathrm{CDCl}_{3}\right)$

7.52-7.55 (m, 2 H, CH(10)), 7.35-7.39 (m, 4 H, CH(1,2,12)), 7.28-7.33 (m, $4 \mathrm{H}$, $\mathrm{CH}(3,11)), 5.38$ (d, $J=6.9 \mathrm{~Hz}, 1 \mathrm{H}, \mathrm{CH}(5)), 3.76$ (ddd, $J=8.3,8.3,6.9,1 \mathrm{H}$, $\mathrm{CH}(6)), 3.04\left(\mathrm{dd}, J=18.1,8.3 \mathrm{~Hz}, 1 \mathrm{H}, \mathrm{CH}_{2}(7)\right), 2.68(\mathrm{dd}, J=18.1,8.3 \mathrm{~Hz}, 1 \mathrm{H}$, $\left.\mathrm{CH}_{2}\left(7^{\prime}\right)\right)$ 
Preparation of $( \pm)$-rel-(4R,5S)-Dihydro-4-(phenylseleno)-5-phenylfuran-2(3H)-one (2) from Trimethylsilyl Ester (15), NPSS (6) Acetic Acid, and (Se)HMPA (9) [WRC-XII-054]<smiles>CC(=O)CC=Cc1ccccc1</smiles><smiles>O=C1CCC(=O)N1[SeH]c1ccccc1</smiles>

15

6

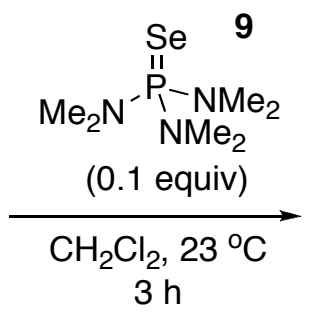

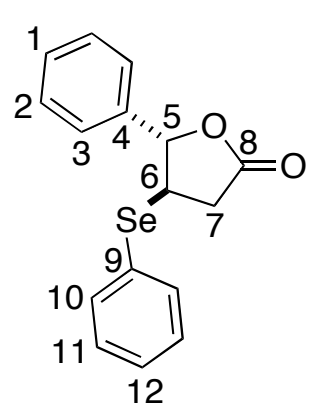

2

To a flame-dried, $25 \mathrm{~mL}$ Schlenk flask equipped with a stir bar under argon was added the $N$-phenylselenylsuccinimide 6 (304 mg, $1.2 \mathrm{mmol}, 1.2$ equiv) and the selenophosphoramide 9 ( $24 \mathrm{mg}, 0.1 \mathrm{mmol}, 0.1$ equiv) in the dry box. After removal from the dry box and reattachment of the flask to a manifold, 6 was diluted with $\mathrm{CH}_{2} \mathrm{Cl}_{2}(8 \mathrm{~mL})$. To the yellow solution was added a solution of (E)-trimethylsilyl-4-phenyl-3-butenoate 15 (234 mg, $1.0 \mathrm{mmol}, 1.0 \mathrm{muiv}$ ), and $\mathrm{AcOH}\left(57 \mu \mathrm{L}, 1.0 \mathrm{mmol}, 1.0\right.$ equiv) in $\mathrm{CH}_{2} \mathrm{Cl}_{2}(2 \mathrm{~mL})$ drop wise over 5 minutes. After $3 \mathrm{~h}$ a saturated aqueous solution of sodium thiosulfate $(5 \mathrm{~mL})$ was added directly to the reaction mixture to quench the remaining $\mathbf{6}$. The biphasic solution was rapidly stirred for an additional 1 h, after which the solution was diluted with $\mathrm{H}_{2} \mathrm{O}(20 \mathrm{~mL})$ and poured into a separatory funnel $(125 \mathrm{~mL})$. The organic phase was extracted with $\mathrm{CH}_{2} \mathrm{Cl}_{2}(3 \times 20 \mathrm{~mL})$, dried over $\mathrm{MgSO}_{4}(3 \mathrm{~g})$, filtered and concentrated in vacuo. The crude residue was directly purified by column chromatography $\left(\mathrm{SiO}_{2}, 80 \mathrm{~g}, 30 \mathrm{~mm}\right.$ x $45 \mathrm{~cm}, 8: 1$ hexanes/ethyl acetate) to afford $288 \mathrm{mg}(91 \%)$ of the pure product $( \pm)-2$.

Data for $( \pm)$-rel-(4R,5S)-dihydro-4-(phenylseleno)-5-phenylfuran-2(3H)-one (2) ${ }^{\mathbf{1}}$ :

${ }^{1} \underline{\text { H NMR: }} \quad\left(500 \mathrm{MHz}, \mathrm{CDCl}_{3}\right)$

7.52-7.55 (m, $2 \mathrm{H}, \mathrm{CH}(10))$, 7.35-7.39 (m, 4 H, CH(1,2,12)), 7.28-7.33 (m, $4 \mathrm{H}$, $\mathrm{CH}(3,11)), 5.38$ (d, $J=6.9 \mathrm{~Hz}, 1 \mathrm{H}, \mathrm{CH}(5)), 3.76$ (ddd, $J=8.3,8.3,6.9,1 \mathrm{H}$, $\mathrm{CH}(6)), 3.04\left(\mathrm{dd}, J=18.1,8.3 \mathrm{~Hz}, 1 \mathrm{H}, \mathrm{CH}_{2}(7)\right), 2.68(\mathrm{dd}, J=18.1,8.3 \mathrm{~Hz}, 1 \mathrm{H}$, $\left.\mathrm{CH}_{2}\left(7^{\prime}\right)\right)$ 


\section{References}

(1) Denmark, S. E.; Edwards, M. G. J. Org. Chem. 2006, 71, 7293.

(2) Schmid, G. H.; Garratt, D. G. Tetrahedron 1978, 34, 2869.

(3) Begtrup, M.; Larsen, P. Acta. Chem. Scand. 1990, 44, 1050.

(4) Lesiv, A. V.; Ioffe, S. E.; Strelenko, Y. A.; Tartakovsky, V. A. Helv. Chem. Acta. 2002, $85,3489$.

(5) Hori, T.; Sharpless, K. B. J. Org. Chem. 1979, 44, 4210.

(6) (a) Nicolaou, K. C.; Claremon, D. A.; Barnette, W. E.; Switz, S. P. J. Am. Chem. Soc. 1979, 101, 3704.; (b) Nicolaou, K. C.; Petasis, N. A.; Claremon, D. A., Tetrahedron 1985, 41, 4835.

(7) Baumgartner, H.; Sullivan, A. C.; Schneider, J. Heterocycles 1997, 45, 1537.

(8) Haynes, R. K.; Indorato, C. Aust. J. Chem. 1984, 37, 1183.

(9) Janssen, R. A.; Kingma, J. A.; Buck, H. M. J. Am. Chem. Soc. 1988, 110, 3018.

(10) Denk, M. K.; Gupta, S.; Brownie, J.; Tajammul, S.; Lough, A. J. Chem. Eur. J. 2001, 7, 4477.

(11) Polet, D.; Alexakis, A.; Tissot-Croset, K.; Corminboeuf, C.; Ditrich, K. Chem. Eur. J. 2006, $12,3596$.

(12) Based upon the procedure developed by: Tomoda, S.; Takeuchi, Y.; Nomura, Y. Synthesis 1985, 212. For a related study see: Back, T. G.; Kerr, R. G. Can. J. Chem. 1986, 64, 308-309. 